\section{Anatomical Study of the Cavernous Sinus Emphasizing Operative Approaches}

\section{Kavernöz Sinüsün Operatif Yaklașımlarını Vurgulayan Anatomik Çalıșma}

\begin{abstract}
AIM: The aim of this article is to describe the microsurgical anatomy of the cavernous sinus, the triangles, and the osseous relationships in the region with special attention to the relationships important in surgical approaches on the intracavernous structures.

MATERIAL and METHODS: Fifty cavernous sinuses obtained from twenty-five cadaver heads were studied in detail using magnification. Stepwise dissections of the cavernous sinuses performed to demonstrate the intradural and extradural routes, anatomy of the triangles and osseous relationships in the region.

RESULTS: The main branches of the intracavernous portion of the carotid artery were the meningohypophyseal, the inferior cavernous sinus, and McConnell's capsular artery. The main branches of the meningohypophyseal trunk were the tentorial, the dorsal meningeal, and the inferior hypophyseal artery. There were variations of the main branches of the meningohypophyseal trunk. The sixth cranial may splite into rootlets as it passes lateral to the carotid artery. There were size and shape variation of the triangles.
\end{abstract}

CONCLUSION: A precise understanding of the bony relationships, the anatomy of the triangels and neurovascular content of the cavernous sinus, together with the use of cranial base and microsurgical techniques are necessary for safer surgery. A single approach is not capable of providing exposure of all parts of the sinus.

KEYWORDS: Microsurgical anatomy, Cavernous sinus, Microsurgery, Carotid artery, Cranial nerves, Triangles

\section{ÖZ}

AMAÇ: Bu çalışmanın amacı cavernöz sinüs, üçgenler ve bölgedeki kemik yapı ilişkilerinin mikrocerrahi anatomisini, intrakavernöz yapılara yapılacak cerrahi yaklaşımda önemli olan ilişkilere özel bir önem vererek tanımlamaktır.

YÖNTEM ve GEREÇ: Yirmibeş kadavra başından elde edilen elli kavernöz sinüs büyütme kullanılarak ayrıntılı olarak çalışıldı. İntradural ve ekstradural yolları, üçgenlerin anatomisini ve bölgedeki kemik ilişkilerini göstermek amacı ile kavernöz sinüslere kademeli diseksiyon uygulandı.

BULGULAR: Karotid arterin intrakavernöz parçasının üç ana dalı meningohipofizeal, inferior kavernöz sinüz ve McConnell kapsüler arteriydi. Meningohipofizeal trankın üç ana dalı, tentorial, dorsal meningeal ve inferior hipofizeal arterdi. Meningohipofizeal trankın ana dallarının varyasyonları vardı. Altıncı kranial sinir karotid arterin lateralinden geçerken rutletlere bölünebilir. Üçgenlerin boyut ve şekillerinde değişiklikler vardı.

SONUÇ: Kemik ilişkilerinin, üçgenlerin anatomisinin ve kavernöz sinüsün nörovasküler içeriğinin tam anlaşılmasının yanı sıra kafa tabanı ve mikrocerrahi tekniklerin kullanılması daha güvenli cerrahi için gereklidir. Tek yaklaşım sinüsün tüm bölümlerinin açılması için yeterli değildir.

ANAHTAR SÖZCÜKLER: Mikrocerrahi anatomi, Kavernöz sinüs, Mikrocerrahi, Karotid arter, Kranial sinirler, Üçgenler

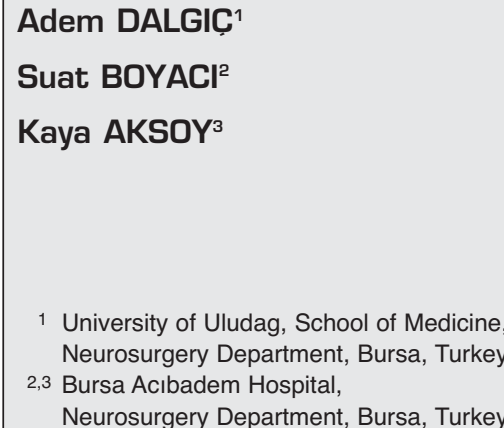

Received : 06.07.2009

Accepted : 02.12.2009

Correspondence address:

Suat BOYACI

Phone : +90 2242704185

E-mail : suatboyaci@hotmail.com 


\section{INTRODUCTION}

Due to the location and connections of the cavernous sinus (CS), anatomists, neurosurgeons, ophthalmologists, neurologists, and endocrinologists have always paid special attention to the subject to understand and explain the complex structure of the sinus. The anatomy of the cavernous sinus has been studied by a number of investigators using gross and microscopic dissection, sectioning of frozen anatomical specimens, and injection and corrosion studies of the venous plexus (7,33-35,51, $52,57,64,66,69,73)$ Parkinson first reported a direct surgical approach to the cavernous sinus in 1965 for a carotid-cavernous fistula (57). Since then, there have been an increasing number of reports of successful direct surgical approaches to arteriovenous fistulae, aneurysms, and neoplasms involving the cavernous sinus $(15,17,24$ $26,28,30,31,33,47,50,54,56)$. The earlier reports involved approaches directed through the lateral wall of the sinus $(17,57)$. Subsequently, approaches to the superior, medial, and inferior parts of the sinus were developed. Cavernous sinus exposure remains a difficult task, because of the complicated neural and vascular relationships of this area.

\section{MATERIALS and METHODS}

Twenty-five tissue blocks containing 50 cavernous sinuses were removed from the cranial base of adult cadavers, fixed in formalin, and examined under 3 to $40 \mathrm{X}$ magnification. Each block contained the sella and both cavernous sinuses. Care was taken to preserve the normal anatomical relationships of the structure. Furthermore, two cadaver heads were used for the transsphenoidal approach. Standard macro- and microsurgical instruments and a high-speed drill with cutting and diamond bits were used. Gross and microscopic 35mm photographs were obtained.

\section{RESULTS}

\section{Arterial relationship}

The internal carotid artery exits the foramen lacerum and enters the posterior-inferior part of the cavernous sinus. It passes upward and forward, to exit the anterior-superior part of the sinus on the medial side of the anterior clinoid process. We found the length of the intracavernous segment to range from 19 to $24 \mathrm{~mm}$ (average $21.5 \pm 2.5 \mathrm{~mm}$ ), and the diameter to range 4.5 to $5.5 \mathrm{~mm}$ (average $5 \pm 0.5 \mathrm{~mm}$ ).
The intracavernous portion of the artery was divided into five parts: 1) the posterior vertical segment, 2) the posterior bend, 3) the horizontal segment, 4) the anterior bend, and 5) the anterior vertical segment. We found the length of the parts of the intracavernous segment as fallow: 1) the posterior vertical segment length was found to range from 4 to $6 \mathrm{~mm}$ (average $5 \pm 1 \mathrm{~mm}$ ), 2) the horizontal segment length was found to range 12 to $15 \mathrm{~mm}$ (average $13.5 \pm 1.5 \mathrm{~mm}$ ), 3) the anterior vertical segment length was found to range from 3 to $5 \mathrm{~mm}$ (average $4 \pm 1 \mathrm{~mm}$ ).

The origin and variations in the branches of the intracavernous part of the carotid artery were examined (Table I). The most consistent branches of the carotid artery within the cavernous sinus were the meningohypophyseal trunk, present in $96 \%$ of our specimens, the artery of the inferior cavernous sinus, present in $74 \%$, and McConnell's capsular arteries, present in $10 \%$. Less frequent branches of the intracavernous carotid were the ophthalmic artery, present in $2 \%$.

Table I: Intracavernous Carotid Branches

\begin{tabular}{|l|c|}
\hline Branches & $\begin{array}{c}\text { Present } \\
(\%)\end{array}$ \\
\hline Meningohypophyseal trunk & $96 \%$ \\
\hline Artery of the inferior cavernous sinus & $74 \%$ \\
\hline McConnell's capsular artery & $10 \%$ \\
\hline Carotid origin of the tentorial artery & $12 \%$ \\
\hline $\begin{array}{l}\text { Intracavernous origin of the ophthalmic } \\
\text { artery }\end{array}$ & $2 \%$ \\
\hline Trigeminal artery & - \\
\hline
\end{tabular}

The meningohypophyseal trunk typically arises from the central one-third of the convex outer margin of the posterior bend. The trunk gives rise to three branches (Figure 1): the tentorial artery (artery of Bernasconi-Cassinari), which passes backward to the tentorium; the inferior hypophyseal artery, which passes medially to the pituitary gland; and the dorsal meningeal artery, which supplies the dura on the upper clivus.

There were two types of meningohypophyseal trunk: complete and incomplete (Figure 1,2, Table II) 
Table II: Meningohypophyseal Trunk and Variations of the Meningohypophyseal Trunk

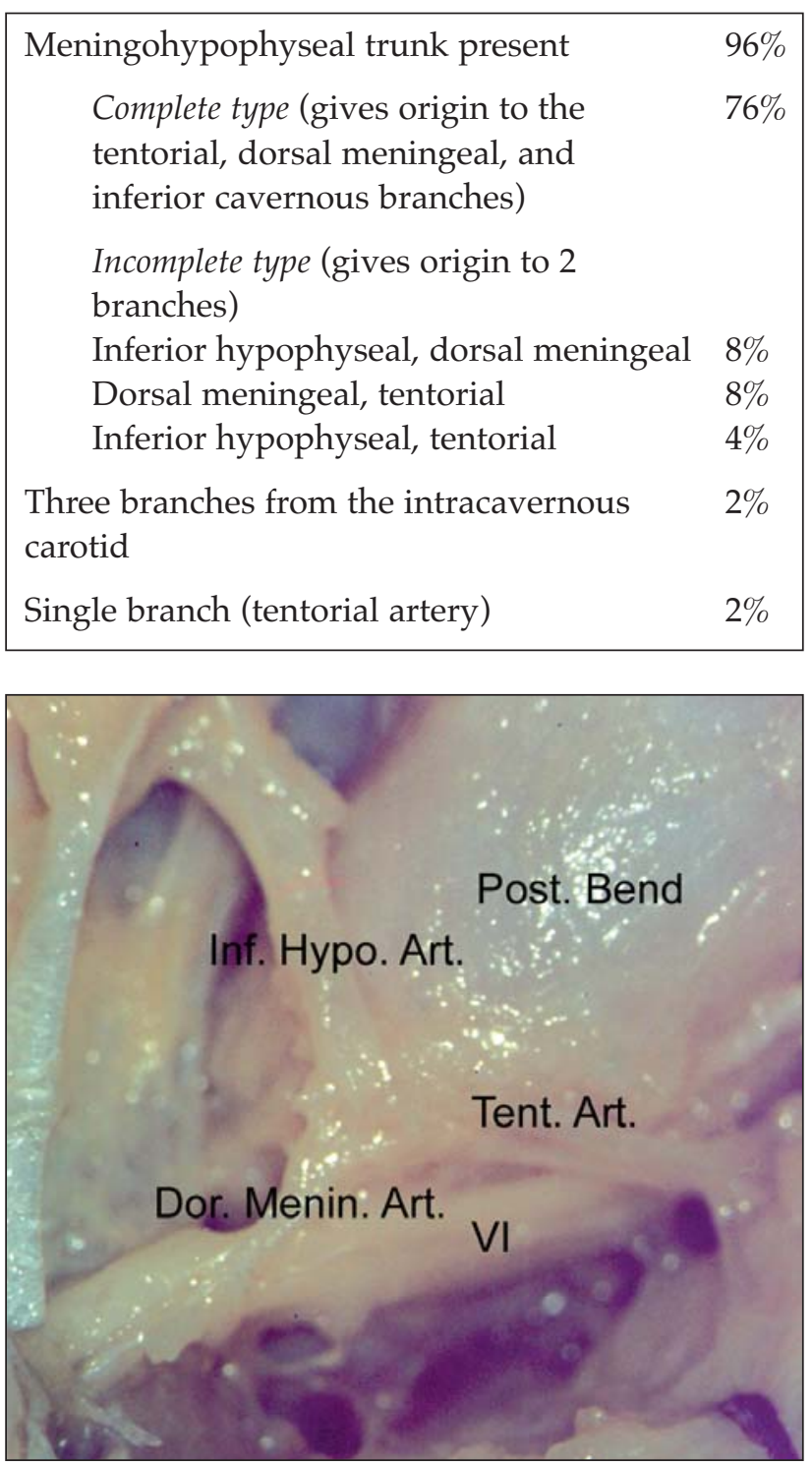

Figure 1: The meningohypophyseal artery typically arises from the central one-third of the convex outer margin of the posterior bend. This trunk gives rise to three branches: the tentorial artery (Tent. Art.), which passes backward to the tentorioum; the inferior hypophyseal artery (Inf. Hypo. Art.), which passes medially to the pituitary gland; and the dorsal meningeal artery (Dor. Menin. Art.), which supplies the dura on the upper clivus. Post. Bend, posterior bend; VI, sixth cranial nerve.

The complete type gave rise to all three branches. In the incomplete type, one or more of the three branches arose directly from the carotid artery. We found that $76 \%$ of the meningohypophyseal arteries were of the complete type and $24 \%$ were of the incomplete type. Infrequently, all three branches arose directly from the carotid artery.

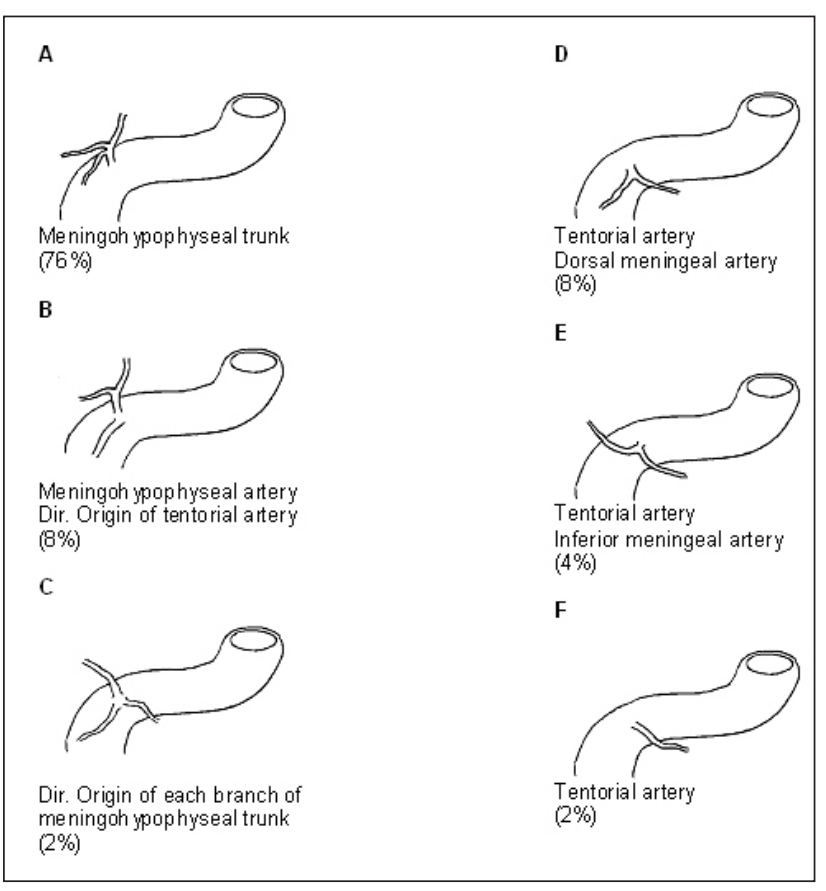

Figure 2: Variations of meningohypophyseal trunk.

The tentorial artery, the most constant branch of the meningohypophyseal trunk, present in $100 \%$ of instances, passed posterolaterally to the roof of the cavernous sinus and along the free edge of the tentorium, gave branches to the third and fourth nerves, and anastomosed with the meningeal branches of the ophthalmic artery and its mate of the opposite side.

The dorsal meningeal artery arose from the meningohypophyseal trunk in $94 \%$ of specimen. It passed posteriorly through the cavernous sinus to the dura over the dorsum, sent a branch to the sixth cranial nerve, and anastomosed with its mate of the opposite side. In $2 \%$, the dorsal meningeal artery arose directly from the carotid.

The inferior hypophyseal artery, the least frequent of the three common branches of the meningohypophyseal trunk, was present in $90 \%$ of specimens. It passed medially to the posterior pituitary capsule and lobe and anastomosed with its mate of opposite side after supplying the dura of the sellar floor.

The artery of the inferior cavernous sinus arose from the inferolateral side of the midportion of the horizontal segment of the intracavernous carotid approximately $8 \mathrm{~mm}$ distal to the origin of the meningohypophyseal trunk (Figure 3). Duplication 


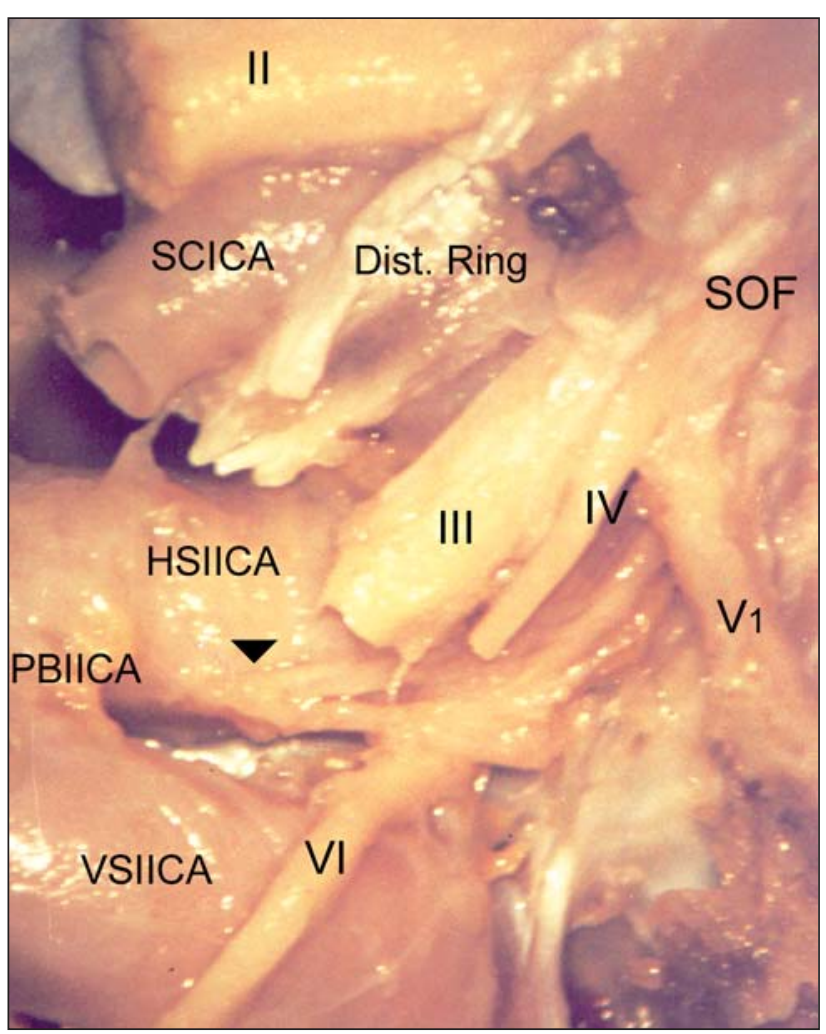

Figure 3: The artery of the inferior cavernous sinus typically arises from the central one-third of the inferior or lateral surface of the horizontal segment and passes above the abducent nerve. Inferior cavernous sinus artery may duplicate as showed in figure. II-III-IV-V1-VI, cranial nerves; SCICA, supraclinoid ICA; Dist. Ring, distal ring; SOF, superior orbital fissure; HSIICA, horizontal segment of the intracavernous ICA; PBIICA, posterior bend of the intracavernous ICA; VSIICA, vertical segment of the intracavernous ICA; $\boldsymbol{\nabla}$ the artery of the inferior cavernous sinus.

of the artery of the inferior cavernous sinus was present in half of the sinuses. In the other half of sinuses, the main branch was gave rise two branches after a short course to laterally. The artery of the inferior cavernous sinus passed over the sixth nerve and downward medial to the ophthalmic division of the fifth nerve to supply the dura of the inferior lateral wall of the cavernous sinus and the area of the foramina ovale and spinosum.

Branche identified as McConnell's capsular artery, which arose from the medial aspect of the horizontal segment and passed to the capsule of the pituitary gland. It was found in $10 \%$ of specimens (Figure 4).

The ophthalmic artery arose within the cavernous sinus, rather than in the usual supraclinoidal location, in one sinus (2\%) (Figure 5).
The ophthalmic artery arising in the sinus passed through the superior orbital fissure to reach the orbit.

A persistent trigeminal artery was not encountered any of the specimens.

\section{Neural relationship}

The oculomotor and trochlear nerves and the first divisions of the trigeminal nerve lie between the two layers of dura forming the lateral wall of sinus (Figure 6). The locations of the nerves from superior to inferior were the third nerve superiorly with the trochlear, abducens, and the first and second divisions of the trigeminal nerve. The outer layer was consistently thicker and more complete than the inner layer. The oculomotor nerve pierced the sinus roof lateral to the posterior clinoid process and was coursed in the upper part of the lateral wall. This nerve exited the sinus by passing below the lower margin of the anterior clinoid process to enter the superior orbital fissure. This nerve provides a good landmark for opening the lateral wall of the sinus (Figure 7, Table III). The trochlear nerve entered the roof of the sinus posterolateral to the oculomotor

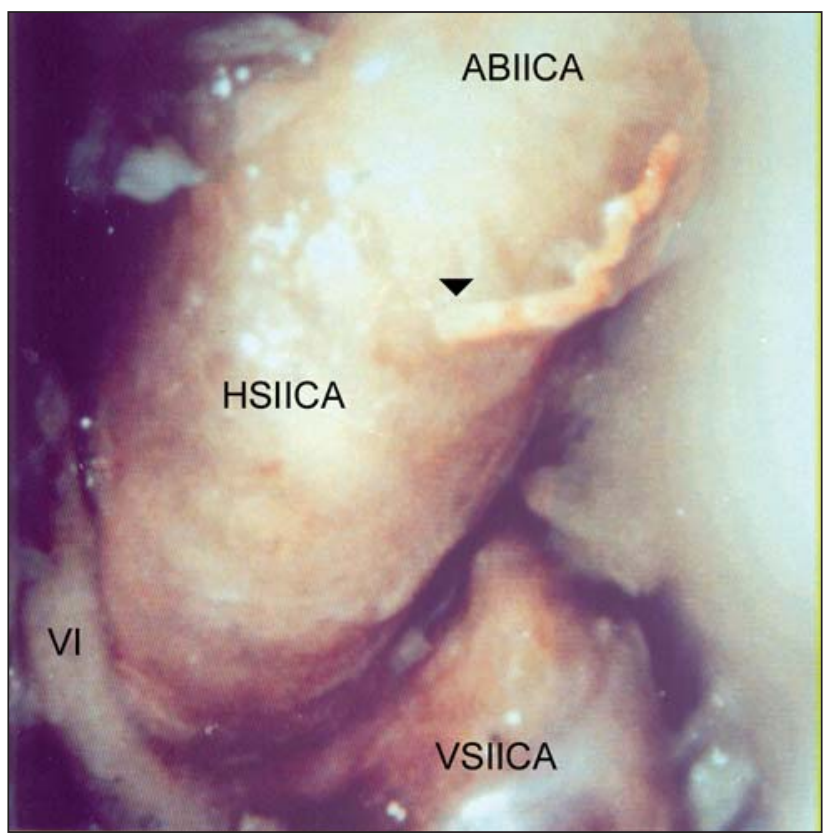

Figure 4: McConnell's capsular artery arises from the medial aspect of the horizontal segment and passes to the capsule of the pituitary gland. HSIICA, horizontal segment of the intracavernous ICA; ABIICA, anterior bend of the intracavernous ICA; VSIICA, vertical segment of the intracavernous ICA; VI, sixth cranial nerve; $\boldsymbol{\nabla}$, McConnell's capsular artery. 


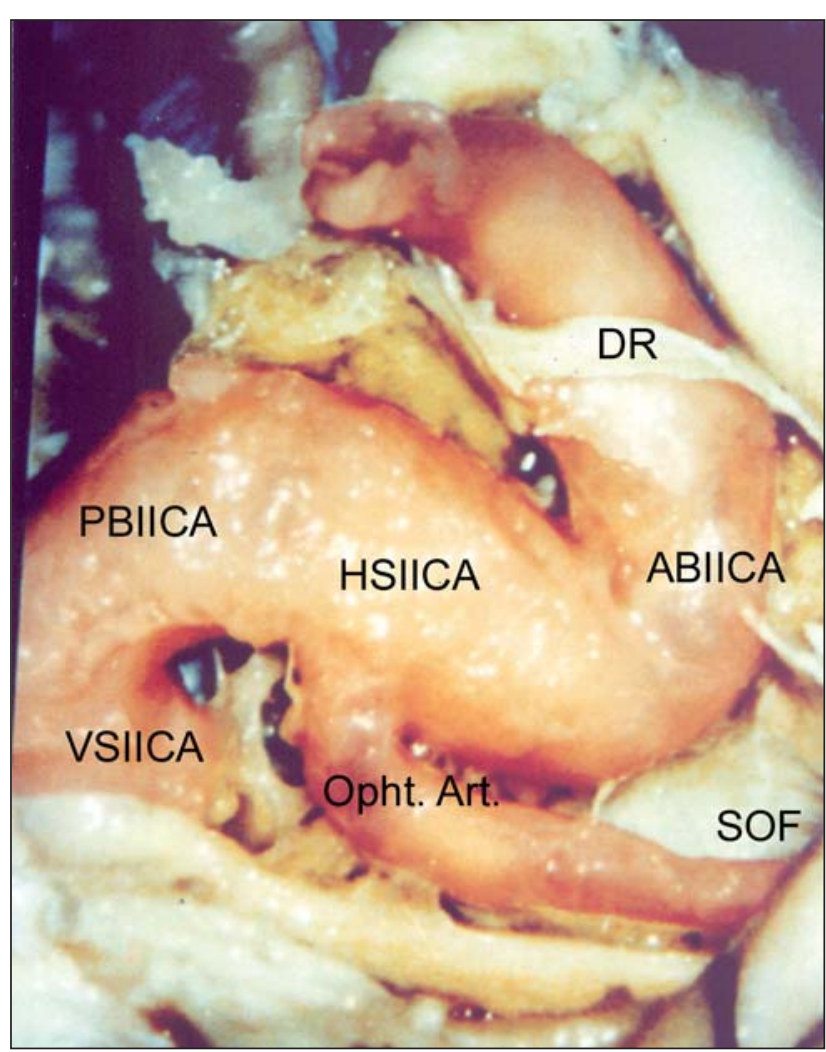

Figure 5: The ophthalmic artery sometimes arises from carotid artery in the cavernous sinus, rather than in the usual supraclinoidal location as shown in figure. The ophthalmic arteries arising in the sinus passes through the superior orbital fissure to reach the orbit. $D R$, dural ring; $S O F$, superior orbital fissure; ABIICA, anterior bend of the intracavernous ICA; PBIICA, posterior bend of the intracavernous ICA; HSIICA, horizontal segment of the intracavernous ICA; VSIICA, vertical segment of the intracavernous ICA; Opht. Art., ophthalmic artery.

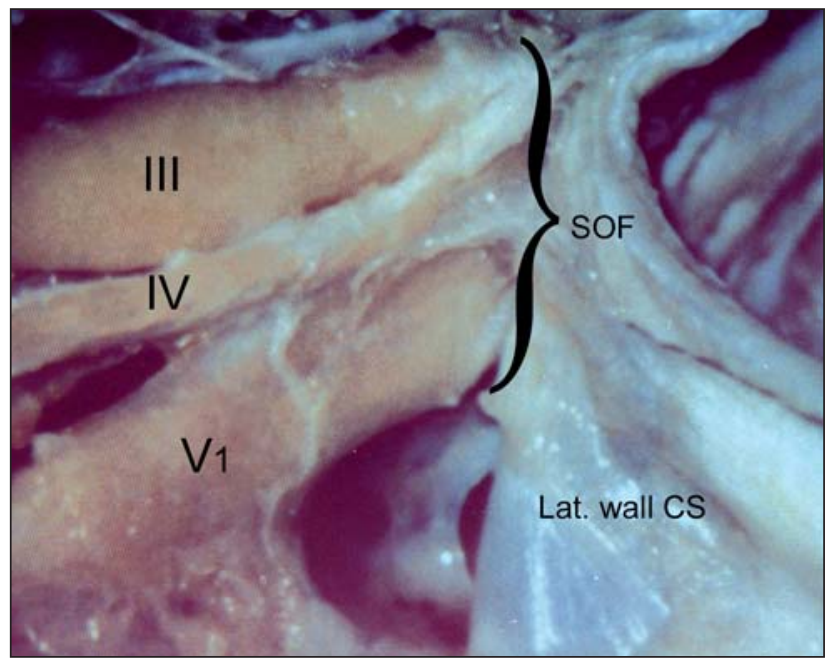

Figure 6: Lateral wall of the cavernous sinus. III-IV-V1, cranial nerves; Lat. Wall CS, lateral wall of the cavernous sinus; SOF, superior orbital fissure.

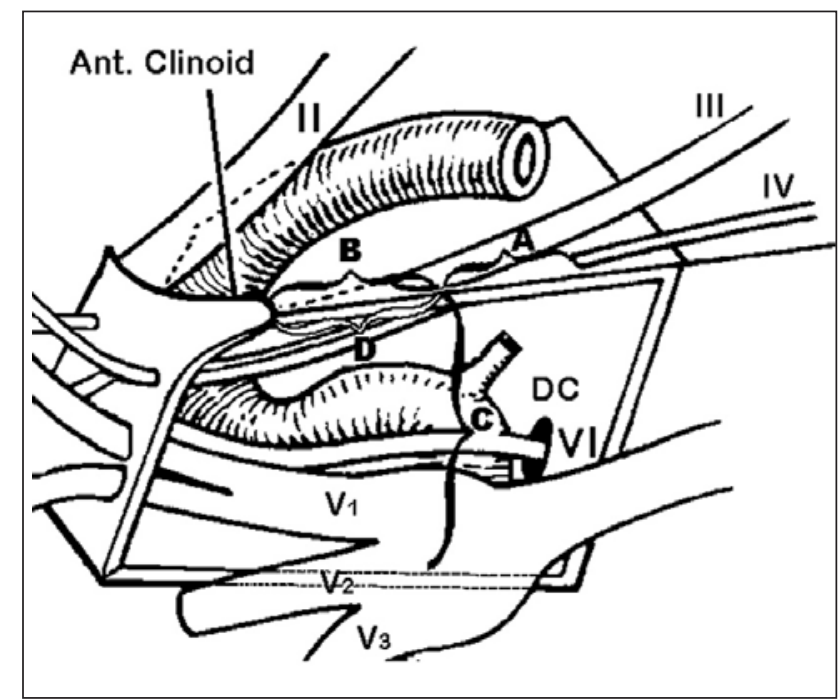

Figure 7: A, entrance of the oculomotor nerve into the roof of the sinus to entrance of the trochlear nerve into the roof of the sinus; $\boldsymbol{B}$, entrance of the oculomotor nerve into the roof of the sinus to anterior margin of the carotid artery at the exit from the cavernous sinus; $C$, entrance of the oculomotor nerve into the roof of the sinus to floor of the sinus; $D$, entrance of the oculomotor nerve into the roof of the sinus to anterior clinoid tip; II, III, IV, V1-V2-V3, VI, cranial nerves; DC, Dorello's canal.

Table III: Measurement in 50 Cavernous Sinuses

\begin{tabular}{|c|c|}
\hline Site on Illustration & \multicolumn{1}{|c|}{ Range } \\
\hline A & $7.53 \pm 1.59$ \\
\hline B & $6.81 \pm 1.93$ \\
\hline C & $11.73 \pm 1.53$ \\
\hline D & $6.53 \pm 1.59$ \\
\hline
\end{tabular}

nerve and below and medial to the free edge of the tentorium. The third and fourth nerves are closely approximated and run together within the dural roof of the cavernous sinus throughout their course to the superior orbital fissure.

The ophthalmic division of the fifth cranial nerve enters the lower part of the lateral wall of the sinus and runs obliquely upward to pass through the superior orbital fissure.

The abducent nerve enters the cavernous sinus through Dorello's canal of the clivus. This canal is situated between the petroclinoid ligament and the upper surface of the petrous apex. The sixth nerve enters from the clivus and bends laterally around the proximal portion of the cavernous carotid artery and 
runs medially and parallel to the ophthalmic division of the fifth nerve. It course within the sinus. Inoue at al. reported that it may split into as many as five distinct rootlets (33). We found that the abducent nerve was not always a single trunk in the cavernous sinus but that it frequently split into multiple rootlets. This nerve consisted of one rootlet in $50 \%$, two in $40 \%$ and three or more in $10 \%$ of specimens.

\section{Osseous relationship}

The results of some measurements are showed in Figure 8 and Table IV.

The anterior clinoid process is located at the medial end of the lesser wing and forms the lateral wall of the intracranial end of the optic canal. The middle clinoid process is situated lateral to the tuberculum sellae and lays media to the carotid sulcus. The posterior clinoid process is located at the

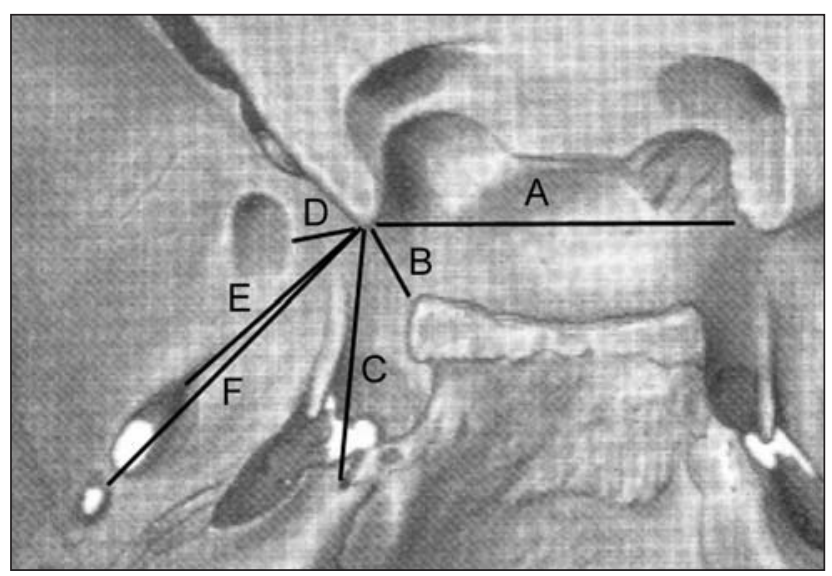

Figure 8: $A$, distance between the anterior clinoid tips; $\boldsymbol{B}$, anterior clinoid tip to the posterior clinoid tip; $\boldsymbol{C}$, anterior clinoid tip to the petrous apex; D, anterior clinoid tip to the foramen rotundum; $\boldsymbol{E}$, anterior clinoid tip to the foramen ovale; $\boldsymbol{F}$, anterior clinoid tip to the foramen spinosum.

Table IV: Osseous Measurements

\begin{tabular}{|c|c|}
\hline Site on Illustration & Range $(\mathbf{m m})$ \\
\hline A & $22.04 \pm 2.37$ \\
\hline B & $6.80 \pm 1.97$ \\
\hline C & $19.13 \pm 1.99$ \\
\hline D & $13.20 \pm 1.89$ \\
\hline E & $17.20 \pm 3.52$ \\
\hline F & $25.26 \pm 3.39$ \\
\hline
\end{tabular}

superolateral margin of the dorsum sellae. The presence of a fibrous or osseus bridge between the tip of the anterior clinoid process and either the middle or posterior clinoid processes makes removal of the anterior clinoid process more difficult and increases the risk of this removal, especially if an aneurysm is present. An interclinoid osseous bridge created by the union of the tips of the anterior and posterior clinoid processes was found in $8.68 \%$ of Keyes' skulls (42). In the study reported here, we defined the incomplete type as one in which the separation between the anterior and posterior clinoid processes was $3 \mathrm{~mm}$.

Removing the anterior clinoid process is an important step in exposing the structures in the superior part of the cavernous sinus. A normal anterior clinoid process is solid, but it may contain an air cell that communicates with the sphenoid sinus. Removing this process, which is situated lateral to the carotid artery, creates a small space within the dura that is called the clinoid space. The lateral aspect of the upper part of the intracavernous segment of the carotid artery is found in the medial wall of the space, where it is covered by the thin dura on the medial side of the anterior clinoid process. The segment, approximately $5 \mathrm{~mm}$ in length, exposed in the clinoid space is called the clinoid segment. This segment of the artery may be damaged during the removal of the anterior clinoid process. Two membranes are found in the cavernous sinus at the level of the clinoid portion of the artery. One, called the carotid dural ring is a very tough dural band that is tightly attached to the artery at the level of the roof of the cavernous sinus. The lateral part of the ring is usually thicker and wider than the medial part. The medial part of the ring is continuous with the dura of the diaphragma sellae. The other membrane, the carotico-oculomotor membrane, stretches from the lateral side of the carotid artery, across the gap between the artery and the oculomotor nerve, and finally medial to the oculomotor nerve to the posterior clinoid process. The anterior part of this membrane, which is very thin, separates the cavernous sinus from the clinoid space. This membrane is attached superiorly to the interclinoid ligament and fold.

\section{Triangles}

The points of entry of cranial nerves are relatively fixed and provide important anatomical landmarks for safe surgical entry into the cavernous sinus. After 
Parkinson's initial description of a triangle in the lateral wall of the cavernous sinus (57), a number of other triangles in this region have been described by other authors (Figure 9).

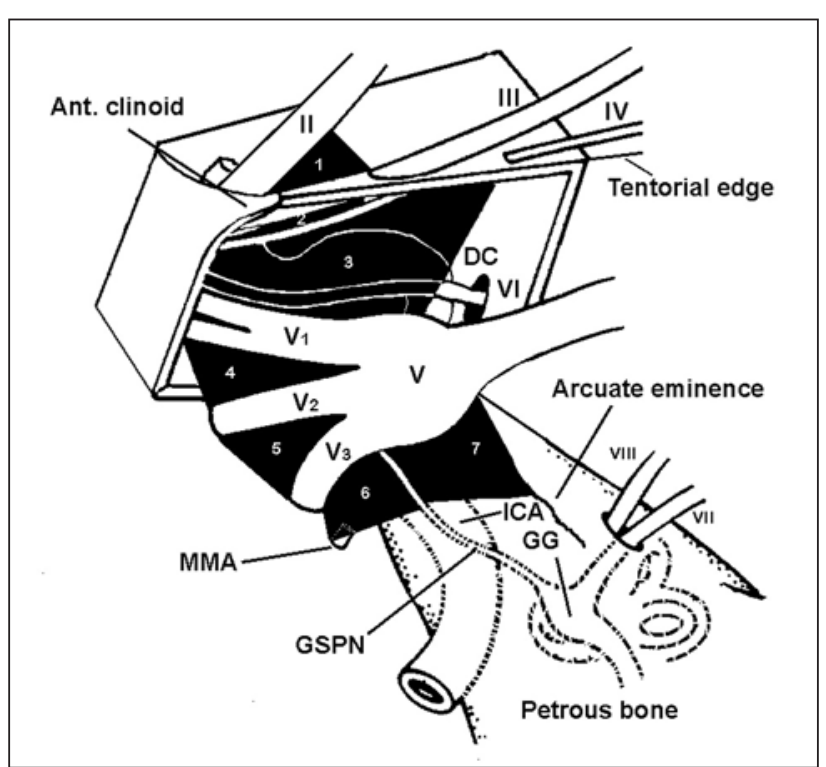

Figure 9: 1, anteromedial triangle(clinoidal, anterior); 2, paramedial triangle (oculomotor); 3, superolateral (Parkinson's, infratrochlear) triangle; 4, anterolateral triangle (anteromedial middle fossa, Mullan); 5, lateral triangle (anterolateral middle fossa, far-lateral); 6, posterolateral (Posterolateral middle fossa, Glasscock's) triangle; 7, posteromedial (Kawase-Shiobara's, Kawase's) triangle; II, optic nerve; III, oculomotor nerve; IV, trochlear nerve; VI, abducent nerve; VII, facial nerve; VIII, vestibulocochlear nerve; V1-V2-V3, divisions of trigeminal nerve; DC, Dorello's canal; GG, geniculate ganglion; GSPN, greater superficial petrosal nerve; MMA, middle meningeal artery; ICA, internal carotid artery.

The clinoidal triangle contains the optic strut anteriorly, the subclinoidal segment of the ICA in the middle, and the roof of the CS posteriorly, which are exposed after drilling of the anterior clinoid process. Sometimes a mucous membrane of the sphenoidal sinus can be exposed anteriorly. The venous plexus that surrounds this part of the ICA can vary in length. Sometimes it reaches only the carotid oculomotor membrane becoming in this part extracavernous (5). There is a fibrous tissue in the medial surface of the oculomotor nerve that divides, according to Dolenc, "the extra-parasellar space from parasellar space compartments" (19), Day (11) and Fukushima (22) described the space that exposes the clinoidal segment of this $1 \mathrm{CA}$ as anterior triangle, which is defined by the lateral border of the intracanalicular optic nerve, the medial wall of the superior orbital fissure dura, and the dural ring surrounding the ICA as it enters the subarachnoid space. They found, with this definition, the following measurements: posterior border averaged $6.30 \mathrm{~mm}$ (range, 5 to $8 \mathrm{~mm}$ ), medial border averaged $6.88 \mathrm{~mm}$ (range, 4.5 to $9 \mathrm{~mm}$ ), and the lateral border averaged 8.72 (range, 6.5 to $9.8 \mathrm{~mm}$ ). However, using the same morphometric parameters Dolenc (19) and defining this space as the anteromedial triangle, the average of the measurements of Watanabe et al. (77) of the medial border, lateral border, and base were, respectively, 9.5, 13.3, and $7.2 \mathrm{~mm}$. The anterior clinoidal process can be pneumatized, communicating with the sphenoidal sinus. The subclinoidal ICA sometimes is surrounded by an osseous bridge between the anterior and middle clinoid process (caroticoclinoidal foramen); in these cases, removing this process in one piece can damage the ICA (80). The epidural removal is recommended, but there have been cases of such a meningioma invading the anterior clinoid process. This structure becomes thick and elongated and intradural removal is necessary (4).

The oculomotor triangle is where the oculomotor nerve enters the roof of the CS. The corners of this space are the anterior and posterior clinoid process and the petrous apex. In these points are connected the anterior and posterior petro clinoid and the interclinoid dural fold. This space exposes the distal intracavernous carotid artery and is an important access corridor for tumor involving the medial CS and for approaches to the interpeduncular fossa. In the Watanabe study, measurements of the medial border, lateral border, and base were, respectively 10.4, 16.1, and $12.2 \mathrm{~mm}$. The medial triangle is the name give by some authors who consider the following corners: subclinoidal carotid segment, posterior clinoid process, and the porus oculomotorius (11). The mean dimensions found by Umansky and Nathan were 9.6 X 16.6 X $13.8 \mathrm{~mm}$ (72).

The supratrochlear triangle is between the oculomotor and trochlear nerves and opening it can expose the posterior bend of the intra cavernous carotid artery and the meningohypophyseal trunk origin (11), whenever the origin of this trunk is more commonly related from the Parkinson's triangle $(31,63)$. In addition, the inferolateral trunk can be 
identified inside this triangle and, less commonly, the medial loop of the ICA (19). The nerves that constitute this triangle cross over the oculomotor nerve before entering into the superior orbital fissure. It is possible to recognize that the nerves that supply the extraocular muscle are irrigated by the inferolateral trunk $(19,44)$. The paramedial triangle is the other name of this space (19).

The infratrochlear triangle, also known as Parkinson's triangle, is bounded by the trochlear nerve and the ophthalmic division of the trigeminal nerve. Generally the meningohypophyseal trunk from the posterior bend of the ICA is located at this triangle, except if the artery is elongated and tortuous. In this case the origin may be pushed upward. The sixth nerve can be exposed through this triangle (19). It was originally described by Parkinson for direct entry into the CS. $(57,58)$ Rhoton et al. found the medial border average to be $13 \mathrm{~mm}$ (range, 8 to $20 \mathrm{~mm}$ ), the lateral border averaged 14 $\mathrm{mm}$ (range, 5 to $24 \mathrm{~mm}$ ), and the posterior border average was $6 \mathrm{~mm}$ (range, 3 to $14 \mathrm{~mm}$ ) (31), but there were triangular spaces not large enough to provide a good surgical exposure. However, this space can be enlarged by dissecting and displacing V1 and the fourth nerve (19). Lateral triangle is the name of this space given by same authors $(11,77)$.

The anteromedial middle fossa triangle, first described by Mullan (53), is situated between the ophthalmic and maxillary nerves. Displacing V1 medially exposes the sixth nerve and the ICA. There is fatty tissue in the anterior part of this space that can be an extension of periorbital fat (19). Removing bone in this triangle will expose the sphenoid sinus. The average of this space, also known as the anterolateral triangle $(11,19,77)$ by Day and Watanabe, of the medial border, lateral border, and base were, respectively, 10.63 and $11.7 \mathrm{~mm}, 10.36$ and $7.8 \mathrm{~mm}, 5.83$ and $12.0 \mathrm{~mm}(11,77)$.

The anterolateral middle fossa triangle is bounded by the second and third divisions of the trigeminal nerve, V3 being shorter than V2. It is called the far-lateral (11) or lateral triangle $(19,77)$. The sphenoidal emissary foramen, in some cases, is located in this space joining the CS with the pterygoid venous plexus. Anterolateral extensions of intracavernous tumors are exposed through this triangle. Retracting its posterior corner can expose the intrapetrous ICA. Opening the bone in the medial wall of this space exposes in some cases the lateral wall of the sphenoid sinus. The measurements of Day and Watanabe of the medial border, lateral border, and base were, respectively, 10.03 and 13.9 $\mathrm{mm}, 7.54$ and $15.5 \mathrm{~mm}$, and 10.53 and $7.6 \mathrm{~mm}$.

The posterolateral middle fossa triangle or posterolateral triangle $(19,77)$ was defined by Glasscock originally with the corners being the posterior rim of the foramen ovale, the apex of the cochlea, and the posterior border of the mandibular division of the trigeminal nerve (5). Rhoton defines this space by the lateral surface of the mandibular nerve distal to the point at which the greater petrosal nerve crosses below the lateral surface of the trigeminal nerve and by the anterior margin of the greater petrosal nerve (63).

The posteromedial middle fossa triangle, also known as Kawase's triangle, Kawase-Shiobara's triangle, or the posteromedial triangle, is defined by the porus trigeminus, the cochlea, and the mandibular division of the trigeminal nerve $(5,11)$. Rhoton defined one of the sides as the line between the hiatus fallopii to the dural ostium of Meckel's cave (63). This triangle may be removed for entry into the posterior CS and as an entry point to the posterior fossa through the petrous apex (anterior petrosectomy). Drilling the lateral apex of this triangle exposes the cochlea. The petrous carotid crosses the anterior margin of this triangle and proximal control of this vessel can be achieved here.

The inferolateral paraclival triangle has the follows corners, entry sites of the trochear and abducens nerves, and the site where the first petrosal vein joins to the superior petrosal sinus. Day considers this space (the posteroinferior triangle) bounded by the porus trigeminalis, the entrance of the sixth nerve in Dorello's canal, and the fourth cranial nerve entrance along the incisura into the lateral wall of the CS (11). The authors have adopted the definition of Dolenc, who, in addition, divides this space by a line between the entry point of the petrosal vein and the anterior limit of the entry point of the fifth cranial nerve, in the "tentorial triangle" and "osseous triangle" (19) above and below the fifth nerve, respectively. The first contains the tentorial artery, also known as the BernasconiCassinari artery, the superior petrosal sinus, and the tentorium superior and posterior to Meckel's cave. The osseous triangle corresponds to Kawase's triangle in the 
middle fossa and contains the entry point of the fifth nerve.

The inferomedial paraclival triangle is bounded by the posterior clinoid process, the dural entrance of the trochlear and abducens nerve. This space extends in the posterior sinus wall. The lateral edge of the dorsum sellae, petroclival fissure, and Dorello's canal can be exposed after drilling of the medial part of this space. The contents of this triangular space are the abducens nerve, the posterior genu of the 1CA, the dorsal meningeal artery, the basilar venous plexus, and the posterior petroclinoid fold $(13,19)$.

While some authors do not describe all the spaces mentioned above, others $(5,11)$ consider another two spaces: the pre- and postmeatal spaces. The premeatal space is defined by the intrapetrous carotid genu, the geniculate ganglion, and the medial lip of the porus acusticus and is used to locate the cochlea during extradural drilling of the medial fossa. The postmeatal triangle is bounded by the internal auditory canal, superior semicircular canal, and the petrous ridge.

CS has five walls: lateral and medial walls, a roof, and posterior and anterior walls and the region in and around it can be divided into 10 triangels: clinoidal (anterior,anteromedial), oculomotor, supratrochlear (paramedian), infratrochlear (Parkinson's), anteromedial middle fossa, anterolateral middle fossa (Glasscock's), posteromedial middle fossa (Kawase's), inferolateral paraclival, and inferomedial paraclival (63).

\section{Surgical Approaches}

Interest in direct surgical approaches to lesions of the cavernous sinus has grown as neuroradiological imaging and microsurgical technique have improved. A number of different routes to the cavernous sinus have been described, including the subtemporal approach through the lateral wall $(14,33,52,66)$, the pterional approach through the superior wall $(26,61)$, the transpetrosal-transtentorial approach through the posterior wall (27), the contralateral pterional transsylvian approach through the medial wall $(26,61)$, and the transsphenoidal approach through the inferior wall (46). Most of these approaches can be broadly classified as either extradural or intradural. Dolenc (15), however, described a combined extradural- intradural approach that has been commonly used for lesions in this region.

The operative approach to the superior, lateral, medial, and inferior part of the cavernous sinus were examined in this study.

\section{Superior Intradural Approach}

The superior intradural or extradural approach is directed through a frontotemporal craniotomy. Dolenc usually removes the anterior clinoid process and opens the optic canal before opening the dura mater $(15,17)$. During removal of the lateral orbital wall between the superior orbital fissure and the foramen rotundum, care should be taken not to damage the orbital periosteum (32). In contrast, Hakuba et al. first open the dura mater and then expose the anterior clinoid process and the medial sphenoid ridge, which are resected with extensive unroofing of the optic canal $(25,28)$. Sekhar et al. described the triangular area of the roof after removal of the anterior clinoid process together with the thin underlying dura mater as the "Clinoid space" (66), Day and Fukushima as the "Anterior triangle" $(11,22)$, Isolan as the "Clinoidal triangle" (35). This space varies in dimensions according to the size of the anterior clinoid process which occupied the space lateral to the emergence of the ICA from the cavernous sinus.

The triangular space formed by the line between the $\mathrm{C} 2$ origin of the ICA and posterior clinoid process as the medial border, the medial aspect of the third cranial nerve as the lateral border, and the dura extending between the dural entry point of the third cranial nerve and the posterior clinoid process as the posterior border was called the medial triangle by Hakuba et al. $(25,26,30,50)$ and the anteromedial triangle by Dolenc $(16,74)$ (Figure 10A). This triangle is facilitated by the complete removal of the anterior clinoid process and allows good access to the superior space of the cavernous sinus, particularly the $\mathrm{C} 3$ and $\mathrm{C} 4$ portions of the ICA, with less risk of sacrificing arterial branches (17). The origin of the ophthalmic artery is identified by medial displacement of the second cranial nerve. Care must be taken to preserve these branches. The ILT (Inferolateral trunk) can be identified easily. However, the origin of the MHA (Meningohyphophyseal Artery) is difficult to expose, because the MHA originated from the $\mathrm{C} 4$ 
portion in only $2 \%$ of our specimens. One of the important anatomical relationships in the anterior clinoid process is the third cranial nerve passing just below (33), which cleaves the ICA and the third cranial nerve. Therefore, the dissection should be continued along the ICA carefully to prevent injury to the third cranial nerve when removing the lower edge of the anterior clinoid process. Although the third cranial nerve is enveloped by a membranous dural sheath, the fourth cranial nerve is not usually covered, so care must be taken to avoid damage when exposing the fourth cranial nerve. (30) The fifth cranial nerve is not so well exposed by this anteromedial or medial approach as by the lateral approach, and the sixth cranial nerve not at all (Figure 10B).

\section{Lateral Intradural Approach}

The lateral intradural approach was directed either a temporal craniotomy or a frontotemporal craniotomy. In this approach, superolateral (Parkinson's), and anterolateral triangles were examined. The dural incision was made according to the type proposed by Parkinson (57). A far anterior exposure could be obtained by opening the dura between the first and second trigeminal divisions. The anterior bend, anterior inferior venous space, and the abducent nerve could be seen in this area by lifting the first division.

The lateral wall of the sinus is composed of an inner and outer layer. The outer layer is ticker and more complete than inner layer. The oculomotor and trochlear nerves and ophthalmic and maxillary division of the trigeminal nerves are situated between two layers. The ophthalmic division is usually seen through the semitransparent outer layer, but the oculomotor and trochlear nerves are not as distinctly visible through this dura.

The inner layer of dura in the lateral wall is very thin and often incomplete, especially in the Parkinson's triangle. The oculomotor and trochlear nerves are imbedded in the dura in the upper margin of the triangle. The triangle could be enlarged by depressing the ophthalmic division and elevating the trochlear nerve. Inferior displacement of the ophthalmic division exposed the abducent nerve. The posterior-superior, anterior-inferior, and lateral venous spaces and the lateral surface of the posterior vertical and horizontal segments were well
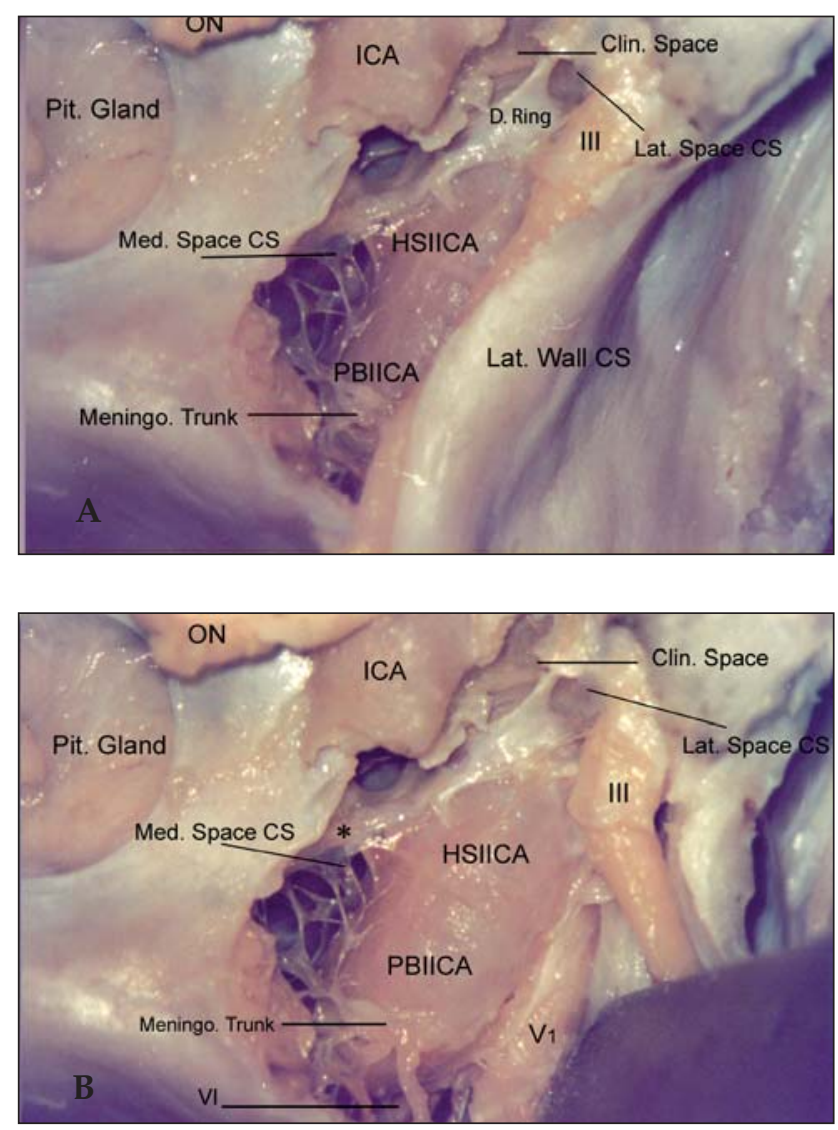

Figure 10A-B: Superior intradural approach. A, The anterior clinoid process has been removed and the clinoid space exposed. $\boldsymbol{B}$, The oculomotor nerve has been displaced laterally to expose the anterior bend, horizontal segment, and the fifth nerve. The dura in the medial wall of the clinoid space has been removed. Opening the dura in the medial wall of the clinoid space exposes the lateral venous compartment. ICA, internal carotid artery; HSIICA, horizontal segment of the intracavernous ICA; PBIICA, posterior bend of the intracavernous ICA; Pit. Gland, pituitary gland; Med. Space CS, medial space of the cavernous sinus; Lat. Space CS, lateral space of the cavernous sinus; Meningo. Trunk, meningohyphophyseal trunk; III, oculomotor nerve; $\mathrm{ON}$, optic nerve; $\boldsymbol{V 1}$, first division of the trigeminal nerve, D. Ring, Dural ring; VI, sixth cranial nerve; *, McConnell's capsular artery.

exposed. Removing the anterior clinoid process exposed the lateral surface of the anterior bend and the anterior vertical segment, so that the lateral surface of the entire cavernous carotid could be seen. The origin of the meningohypophyseal artery and the artery of the inferior cavernous sinus could be identified in most of the specimens. The origin of ophthalmic artery that arose within the sinus could be seen by this route (Figure 11). The pituitary gland could be seen by depressing the horizontal segment. 


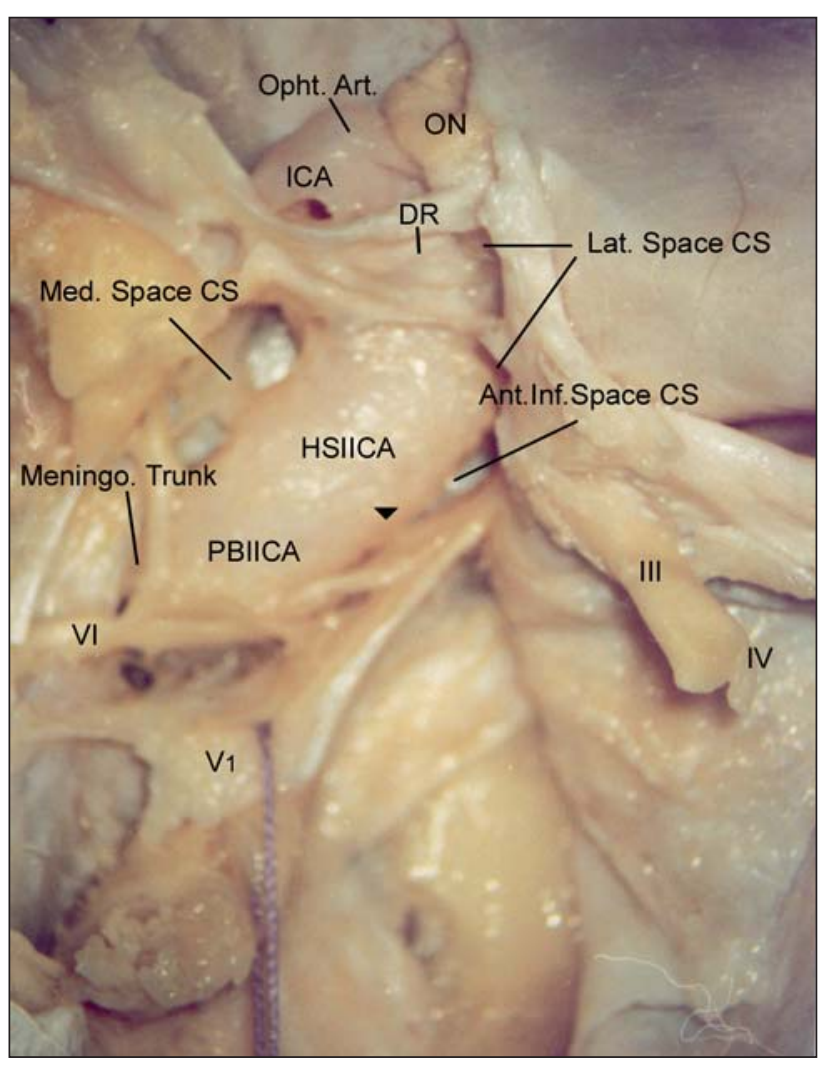

Figure 11: Lateral intradural approach. The lateral wall of the cavernous sinus has been opened to expose the lateral aspect of the horizontal segment, and the origin of the meningohypophyseal artery and the artery of the inferior cavernous sinus. The first trigeminal division has been displaced inferiorly. The anterior-inferior venous space is located below the horizontal segment. ON, optic nerve; III-IV-V1-VI, cranial nerve; Opht. Art., ophthalmic artery; DR, dural ring; ICA, internal carotid artery; HSIICA, horizontal segment of the intracavernous ICA; PBIICA, posterior bend of the intracavernous ICA; Med. Space CS, medial space of the cavernous sinus; Lat. Space CS, lateral space of the cavernous sinus; Ant. Inf. Space CS, anterior inferior space of the cavernous sinus; Meningo. Trunk, meningohypophyseal trunk; $\boldsymbol{\nabla}$, artery of the inferior cavernous sinus.

\section{Lateral Extradural Approach}

The lateral extradural route was directed either through a temporal craniotomy or through a frontotemporal craniotomy. A craniectomy at the lower margin or the bone flap extended the exposure down to the floor of the middle fossa. Lateral triangle was examined. The temporal dura mater is separated from the bony middle cranial fossa to expose the middle meningeal artery, the greater superficial petrosal nerve, facial hiatus, the arcuate eminence, and tympanic tegmen. The branches of the middle meningeal artery are easily identified and the dura mater is separated until the foramen spinosum is exposed. The petrosal artery, a branch of the middle meningeal artery running alongside the greater superficial petrosal nerve, supplies the geniculate ganglion and the seventh cranial nerve (61). The petrosal artery arose proximal to the foramen spinosum in $58 \%$ and distal in $42 \%$ of cases reported by Paullus et al. (61). The greater superficial petrosal nerve, which usually adheres to the surrounding dura, is encountered posterior to the foramen spinosum and provides a reliable landmark for orientation during the approach. As this nerve runs above and parallel to the horizontal segment of the petrous ICA, the petrous bone is drilled off to expose this artery. During bone removal, it is important to remember that the junction of this nerve with the geniculate ganglion is usually covered by bone. However, there is no bony covering in $30 \%$ of cases, and in $15 \%$ of these the bone is also absent over the genu of the seventh cranial nerve and the geniculate ganglion. (55). The facial hiatus, a narrow groove between the trigeminal impression medially and the arcuate eminence laterally, transmits the greater superficial petrosal nerve and the petrosal artery (55). Paullus at al. reported two branches arising from the horizontal segment of the petrous ICA: the Vadian or pterygoid artery (in 30\% of cases) and the periosteal artery (in 8\%). These branches arose predominantly from the inferior $(55 \%)$ or anteroinferior $(35 \%)$ surfaces (61). The entire horizontal portion of the petrous carotid was surrounded by a periosteal sheath that had to be opened to expose the artery. A venous plexus often surrounds the artery inside the sheath.

This approach exposed only the inferior portion of the sinus and the posterior and lateral surface of the posterior vertical segment of the cavernous carotid; however, the junction of the petrous and cavernous segments of the artery was best exposed by this route (Figure 12).

\section{Combined Lateral and Inferolateral Approach}

A temporal or frontotemporal craniotomy performed. Lateral, posteromedial (Kawase's), and posterolateral (Glasscock's) triangle was examined. The floor of the middle fossa lateral to the carotid canal and foramen spinosum and ovale were removed with a drill and rongeur. The temporal dura mater was separated from the floor of the middle fossa to expose the arcuate eminence, the greater 


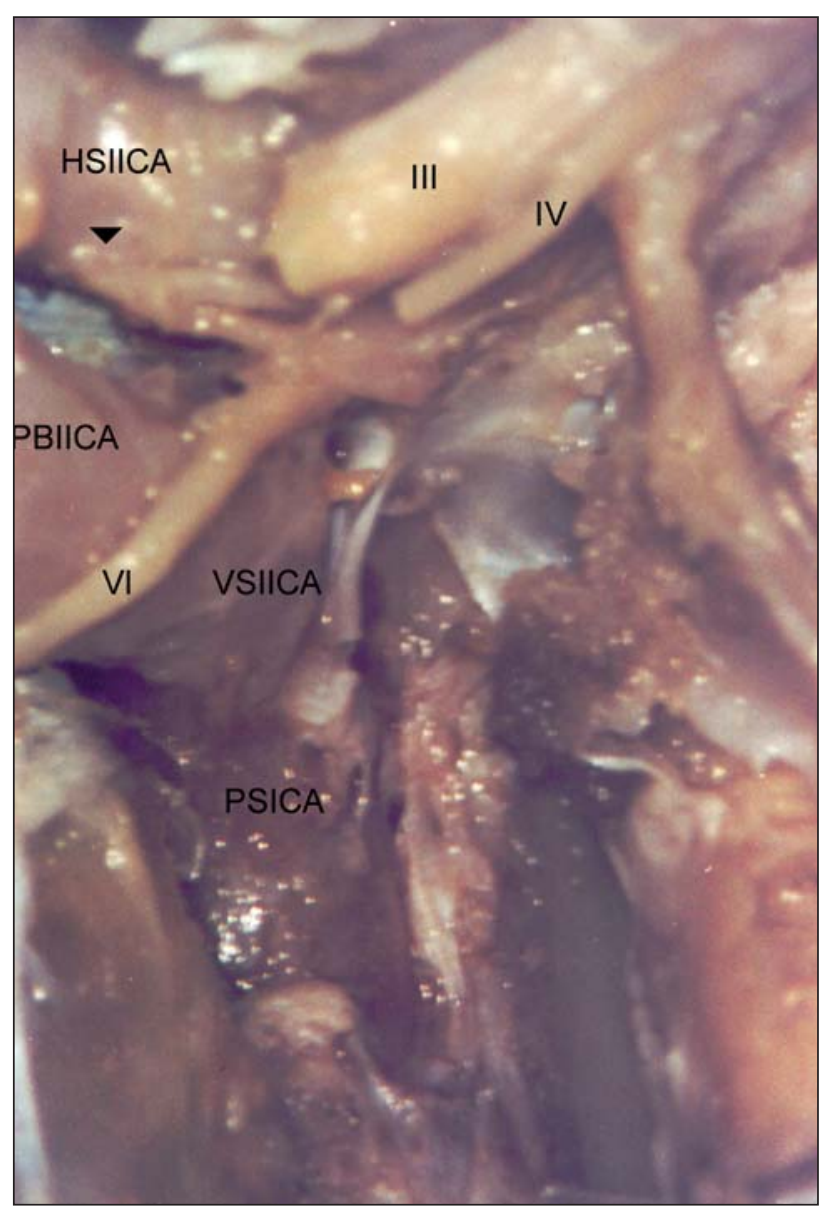

Figure 12: Lateral extradural approach. Bone has been drilled away to expose the petrous segment of the internal carotid artery. The third trigeminal division has been divided at the foramen ovale. The dura has been elevated to expose the vertical segment. The dura forming the lateral wall of the cavernous sinus has been removed to expose the oculomotor and trochlear nerves. The trigeminal nerve has been reflected forward to expose the abducent nerve and the artery of the inferior cavernous sinus. III-IV-VI, cranial nerves; HSIICA, horizontal segment of the intracavernous ICA; PBIICA, posterior bend of the intracavernous ICA; VSIICA, vertical segment of the intracavernous ICA; PSICA, petrosal segment of the ICA; $\boldsymbol{\nabla}$, artery of the inferior cavernous sinus.

petrosal nerve, and the middle meningeal artery. The middle meningeal artery was divided at its emergence from the foramen spinosum. The genu and the vertical segment of the petrous carotid were exposed. The horizontal segment of the petrous carotid was fallowed anteromedially. The maxillary and mandibular divisions and the trigeminal ganglion were exposed extradurally. It was difficult to expose the cavernous sinus unless the mandibular nerve was divided. After dividing the third division above the foramen ovale, the trigeminal ganglion was elevated with the dura. This exposed the junction of the petrous and cavernous carotid and the structures in the inferior lateral portion of the cavernous sinus. The exposure could be extended forward, which would allow the approach to be combined with an intradural approach to the lateral and superior walls of the sinus. With intradural approach lateral wall opened. All structures, except for anteromedial portion of the cavernous sinus, were exposed (Figure 13).

\section{The superior combined extra- and intradural approach}

The superior extradural approach was directed through a large frontotemporal craniotomy. Anteromedial and paramedial triangles were examined. The dura was separated from the orbital roof down to the optic canal and anterior clinoid process and from the sphenoid wings down to the superior orbital fissure. The bone removal included the posterior part of the roof of the orbit, the roof and lateral wall of the optic canal, the lesser sphenoid wing, and the anterior clinoid process. The lateral

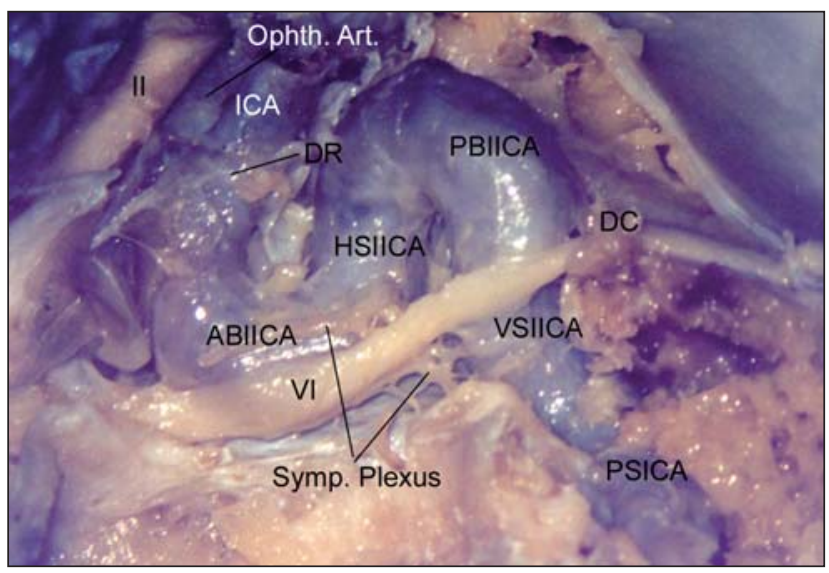

Figure 13: Combined lateral and inferolateral approach. The third trigeminal division has been divided above the foramen ovale and the dura elevated to expose the posterior vertical segment of the cavernous carotid artery. Bone has been drilled away to expose the petrous segment of the carotid artery. This exposed the junction of the petrous and cavernous carotid and the structures in the inferior lateral portion of the cavernous sinus. With intradural approach lateral wall opened. All structures, except for anteromedial portion of the cavernous sinus, were exposed. II-VI, cranial nerves; Symp. Plexus, sympathetic plexus; Ophth. Art., ophthalmic artery; DR, dural ring; DC, Dorello's canal; ICA, internal carotid artery; PBIICA, posterior bend of the intracavernous ICA; HSIICA, horizontal segment of the intracavernous ICA; ABIICA, anterior bend of the intracavernous ICA; PSICA, petrosal segment of the ICA. 
orbital wall between the superior orbital fissure and foramen rotundum was partially removed. At this stage, the clinoid segment of the carotid artery will be visible between the superior orbital fissure and the optic nerve through the thin dura that lines the medial aspect of the anterior clinoid process. The incision in the roof of the sinus was begun in the clinoid space and extended posterolaterally between the carotid artery and the oculomotor nerve toward the posterior clinoid process. The dura surrounding the optic nerve was opened along the full length of the optic canal. Lateral retraction of the lateral wall of the sinus with the enclosed third and fourth cranial nerves provided access to the lateral and posterior-superior venous space, the anterior and lateral surface of the anterior vertical segment and anterior bend, the superior and lateral surface of the horizontal segment, and the origin of the artery of the inferior cavernous sinus. Gently displacing the optic nerve medially exposed the origin of the ophthalmic artery. Posterolateral retraction of the carotid artery exposed the medial venous space and the medial surface of the anterior bend and anterior vertical segment.

\section{The Inferomedial transnasal-transsphenoidal approach}

An inferomedial approach directed through a transnasal-transsphenoidal exposure was used expose the medial wall of the cavernous sinus. The mucosa was elevated and removed from the lateral wall of the sphenoid sinus to expose the bone between the cavernous and sphenoid sinuses. This bone may be very thin or absent, in which case the mucosa of the sphenoid sinus will rest directly against the dura forming the medial wall of the cavernous sinus $(21,33)$. Removing the mucosa and bone in the lateral wall of the sphenoid sinus will expose the dura that forms the medial wall of the cavernous sinus, which is removed to expose the medial venous space and the junction of the cavernous sinus with the basilar sinus. This also exposed the medial and inferior aspects of the posterior bend and horizontal segment and the anterior and medial surfaces of the anterior bend. Medial retraction of the cavernous carotid provides exposure of the lateral venous space and access to the origin of the artery of the inferior cavernous sinus and the abducent nerve (Figure 14A,B).
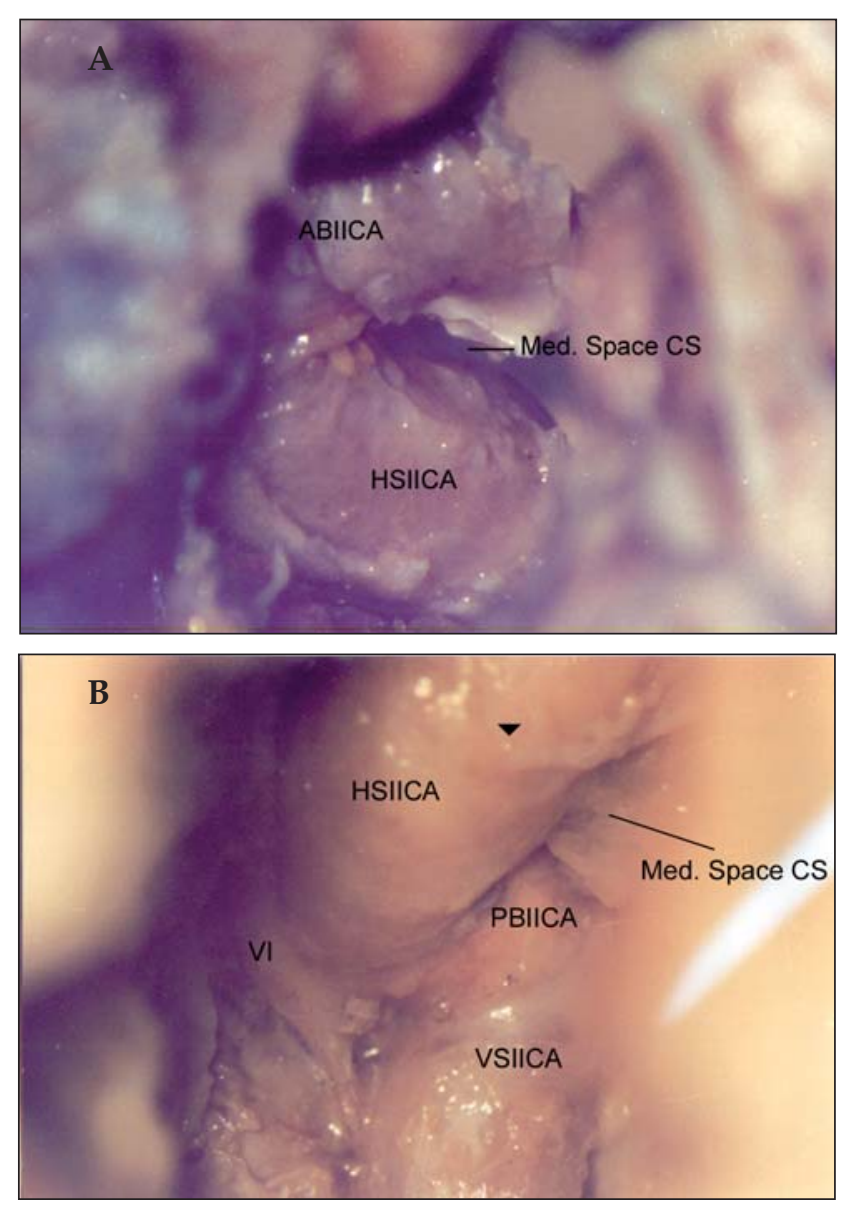

Figure 14A,B: Inferomedial transnasal-transsphenoidal approach. A, Removing the mucosa and bone in the lateral wall of the sphenoid sinus will expose the dura that forms the medial wall of the cavernous sinus, which is removed to expose the medial venous space. This also exposed the medial and inferior aspects of the posterior bend and horizontal segment $\boldsymbol{B}$, Ethmoidal bone has been removed to expose abducent nerve and artery of the inferior cavernous sinus. VI, abducent nerve; Med. Space CS, medial space of the cavernous sinus; ABIICA, anterior bend of the intracavernous ICA; HSIICA, horizontal segment of the intracavernous ICA; PBIICA, posterior bend of the intracavernous ICA; VSIICA, vertical segment of the intracavernous ICA; $\boldsymbol{\nabla}$, artery of the inferior cavernous sinus.

\section{DISCUSSION}

Embryologically, the cavernous sinus begins as an extradural out-pouching between the temporal lobe dura and the perichondrium of the basichondrocranium $(29,78)$. Venous channels develop within this area to form the cavernous sinus in the basal epidural space. The lateral wall contains the third, fourth, and first division of the fifth cranial nerve along with their own dural sheaths $(71,72)$. These sheaths variably merge to form a more or less continuous inner lining that is subsequently overlaid 
by the medial dura of the temporal lobe. The sheaths themselves represent a relative weak spot in the dura surrounding the cavernous sinus and often serve as a conduit for secondary cavernous sinus involvement from surrounding meningiomas (38). In planning for surgery in this area, it is best to remember its embryological origin $(23,65)$.

Anatomically the cavernous sinus can be seen as an extradural parasellar extension of the contents of the orbit (8). The medial wall of the cavernous sinus directly continues as the medial periorbita, through the superior orbital fissure. The lateral wall of the cavernous sinus is formed by the condensation of the sheaths of the third, fourth, and first division of the fifth cranial nerves. This sheath condensation extends anteriorly to join the orbit at the superior orbital fissure, where the lateral wall fuses with the lateral periorbita. Kehrli and colleagues have emphasized the true extradural nature of the cavernous sinus in a series of articles $(39,40,41)$.

The bones adjacent to the cavernous sinus include the body of the sella (medially) and the floor of the middle cranial fossa (inferiorly). The floor of the cavernous sinus extends between the foramen rotundum (anteriorly) and the foramen ovale (posteriorly and laterally). The carotid artery enters the posterior aspect of the cavernous sinus through the floor overlying the foramen lacerum. The anterior clinoid, which represents the terminal portion of the lesser wing of the sphenoid forms the anterior aspect of the lateral wall of the optic canal. Its underlying strut separates the superior orbital fissure from the optic canal. This potential space can be made into a working space by the neurosurgeon. Removal of the anterior clinoid reveals the anterosuperior aspect of the cavernous sinus, and access is provided via the roof of the cavernous sinus through the (anteromedial) triangle formed by the optic nerve (medially) and the third nerve (laterally) (18).

The dural roof of the cavernous sinus continues as the diaphragma sellae, which covers the sella turcica enclosing the pituitary gland (73). The roof of the cavernous sinus extends posteriorly to the clival dura and laterally to the posterior clinoids. The posterior clinoids also mark the rostral termination of the dorsum sellae. The base of the posterior wall of the cavernous sinus is marked by the petroclinoid (Gruber's) ligament, which connects the posterior clinoid to the petrous apex (81). This dural attachment forms the roof of Dorello's canal, which contains the sixth nerve after it enters the dura, and the inferior petrosal sinus on its way to the jugular bulb.

The carotid artery, the largest structure contained within the cavernous sinus, enters the sinus from the carotid canal, which is located within the petrous bone, where the carotid runs just under the greater superficial petrosal nerve and above the Eustachian tube. At the medial end of the carotid canal, it makes a turn (Dolenc's lateralloop) (18) to rise over the area of the foramen lacerum. It enters the floor of the cavernous sinus just medial to Meckel's cave and makes another loop (Dolenc's medial loop) to travel forward in its intracavernous horizontal section. As mentioned, the carotid is usually in close contact with the lateral sella wall and thus the medial wall of the cavernous sinus. A condensation of fibrous tissue separates it from the sella. At the anterior end of the horizontal section, the carotid artery makes its final loop (anterior), reversing its course just under the anterior clinoid and medial to the optic nerve. Two condensations of fibrous tissue, the proximal and distal loops, surround the carotid below and above the clinoid and mark the passage of the carotid, first out of the cavernous sinus, and then into the intradural space $(12,43,67)$. Thus the clinoidal portion of the carotid artery is still extradural.

The lateral wall of the cavernous sinus contains the third nerve superiorly, the fourth nerve just below it, and the first division (the ophthalmic) of the fifth nerve (71). The second division of the fifth nerve (maxillary) forms the inferior lateral border of the cavernous sinus and parallels the first division. The maxillary division runs through the foramen rotundum located just below the inferior aspect of the superior orbital fissure, which transmits the ophthalmic division. As the cranial nerves approach the superior orbital fissure, the third nerve divides into a superior and inferior division. The fourth nerve travels superiorly to cross laterally to medially above the branches of the third nerve. The ophthalmic division of the fifth nerve divides into 3 branches: the lacrimal, frontal, and nasociliary.

Actually, 2 variable sets of carotid branches exit in and around the cavernous sinus $(58,76)$ They are particularly important because they supply blood to the surrounding dura and to the cranial nerves 
running in and around the cavernous sinus. The first of these branches, the meningohypophyseal trunk (62), divides into the tentorial artery, the dorsal meningeal artery, and the inferior hypophyseal artery. The tentorial artery supplies the cranial nerves as they enter the cavernous sinus posteriorly. The second major vessel is the inferolateral trunk, which subsequently divides into 4 branches. The superior 2 branches are critical to the blood supply to the intracavernous third and fourth cranial nerves $(9,10,36)$. Significant collateralization in this area usually protects these nerves, even if the inferolateral trunk is disturbed. Terminal dural branches from the middle meningeal artery (entering the skull through the foramen spinosum ) connect with the branches of the inferolateral trunk to form the artery of the foramen rotundum (accompanying the second division of cranial nerve $\mathrm{V})$ and the artery of the foramen ovale (accompanying the third division of the trigeminal nerve). The inferolateral trunk is variable in location, but is found in the majority of specimens studied. It may rarely arise as a branch of the meningohypophyseal artery at the posterior aspect of the cavernous sinus. There are additional collaterals that join the inferolateral trunk to the accessory meningeal branches that supply the pterygoids and the inferotemporal area below the middle cranial fossa.

Besides the venous channel, the cavernous sinus also contains the sixth nerve, which is located just lateral to the carotid artery, and the sympathetic plexus, which enters the cavernous sinus within the carotid sheath $(1,48,49,59,60,75)$. The pericarotid sympathetic plexus coalesces to form a variable number of trunks, which exit with the sixth nerve to join branches of the fifth nerve entering the superior orbital fissure. In addition, due to its embryological and anatomical connection to the orbit, it is not surprising that fat can be found microscopically in $10 \%$ or more cases $(39,79)$. This finding has produced some confusion because the low signal intensity within the cavernous sinus on computed tomography has suggested a pathological process in patients with other surrounding pathology.

The earliest described pathology of the cavernous sinus relates to its vascular origin. Biumi published a description of a carotid cavernous aneurysm in 1765, and Blane described the results of a postmortem on a woman who had died in 1794 with an intracavernous carotid aneurysm. Adams recognized an aneurysm of the cavernous carotid associated with complete ophthalmoplegia and numbness (2). In his series of intracerebral aneurysms, Bartholow noted a case of a carotid cavernous aneurysm in 1872 (6).

Although various (usually fatal) attempts at draining the cavernous sinus occurred in the 19th century, Krogius is generally credited with the first surgical approach to a "mesothelioma" (likely a meningioma) invading the cavernous sinus. Frazier related the details of a case of cavernous sinus thrombosis, which had been treated surgically in 1900, concluding that "the cavernous sinus is not within the realm of the surgeon's knife" (20) Langworthy suggested that the treatment of cavernous sinus thrombosis "consists in incising and draining the cavernous sinus directly" (45).

Prior to Parkinson's report in 1965, there was little enthusiasm for surgery in this area. As late as 1978, Trobe and coworkers reviewed a series of 6 cavernous meningiomas and 9 aneurysms and concluded that "craniotomy is not recommended" (70). In 1979 J. Lawton Smith commented that "neither of the two lesions (meningioma or aneurysm) in the cavernous sinus should be considered surgical candidates" (68). At almost the same time, Vinko Dolenc after careful anatomical studies, undertook a direct surgical approach to intracarotid vascular lesions in 7 patients, without resorting to modification of the circulation (17). These cases, predicated on Parkinson's pioneering work, were the opening salvo in what has become a barrage of surgical cases involving the cavernous sinus.

The approach to a lesion in the cavernous sinus must be selected based on the site and type of lesion. The superior approach provide the best visualization of the anterior vertical and clinoid segments, the anterior bend, and anterior parts of the lateral and posterior-superior venous space. The lateral approach provides the best exposure of the lateral surface of the posterior vertical and horizontal segments; the posterior bend and the lower part of the anterior bend; the lateral, anterior-inferior and posterior-superior venous spaces; the cranial nerves in the wall of the sinus; and intracavernous course of the abducent nerve. It also provides the best 
visualization of the origin of the meningohypophyseal trunk and the artery of the inferior cavernous sinus. It is clear that a single approach is not capable of providing exposure of all the parts of the sinus; however, a combination of the superior and lateral approaches provides the best exposure of the cranial nerves, the intracavernous carotid, and the venous space above, below, and lateral to the carotid artery (33).

The lateral extradural approach is used to expose the junction of the petrous and cavernous segments of carotid artery. If more proximal exposure is needed, the lateral approach is combined with an inferolateral approach. Further exposure of the ICA underlying the Gasserian ganglion and of the posterior part of the cavernous sinus can only be achieved by dividing the mandibular division of the trigeminal nerve or by adopting a more inferior subtemporal-infratemporal approach. This approach exposed only the inferior portion of the sinus and the posterior and lateral surface of the posterior vertical segment of the cavernous carotid; however, the junction of the petrous and cavernous segments of the artery was best exposed by this route. This approach could be combined with an intradural approach to the lateral wall or with an extra- or intradural approach to the superior wall (33).

The superomedial approach provides the best exposure of the medial side of the anterior vertical and horizontal segments and the anterior bend, the medial venous space, the inferior hypophyseal artery, and the superior, anterior, lateral and anterior surfaces of pituitary gland (33). By a combination of the superior and lateral approaches, most of the intracavernous ICA, all space of the CS, and all of the cranial nerves could be well exposed (66).

The anterior clinoid process lies within the anteromedial triangle and exposure of the anteromedial triangle requires complete extradural removal of the anterior clinoid process. The anterior loop of the carotid artery lies within the floor of this triangle. Approaches to the cavernous sinus commonly involve removal of the anterior clinoid process. Dolenc removes the anterior portion of the anterior clinoid process initially, then separates it from the lateral wall of the optic canal (C7). This detaches the anterior clinoid from the adjacent bone structures, but not from the dura mater overlying the distal portion of the cavernous sinus and the carotid artery. Then the central part of the process is drilled and dissected from the dura. Removal of the clinoid must often be combined with unroofing the orbit, and optic canal, to allow mobilization of the optic nerve and exposure of the origin of the ophthalmic artery (33). The oculomotor nerve may be injured during removal of the lower margin of the anterior clinoid process. The approaches commonly directed through the lateral wall below the anterior clinoid process involve a high risk of extraocular palsy; however, these nerves often recover if they are preserved intact. Sekhar et al. have demonstrated the possibility of nerve grafting or resuturing of the nerves in the region of the cavernous sinus (66).

Intracavernous aneurysms have been approached by the lateral and superior approaches $(28,37,50)$. A superior approach involving removal of the anterior clinoid process may suffice for a small aneurysm in a dural fold at the level of the roof of the sinus. The superior approach may need to be combined with a lateral approach for exposing a large intracavernous aneurysm. In addition, it may prove helpful to expose the petrous carotid proximal to the sinus by an extradural route if temporary occlusion is needed to control bleeding within the sinus. Tumors involving the cavernous sinus often require a combination of these approaches, which may need to be done in stages.

Currently, most carotid-cavernous fistulae are treated by intravascular embolization or by balloon occlusion techniques. These fistulae, if approached directly, have usually been exposed by a lateral approach directed through Parkinson's triangle. In a previous study by Fujii et al. it was demonstrated that the cavernous sinus could be entered through the thin lateral wall of the sphenoid sinus (21), and Laws et al. reported a case of carotid-cavernous fistula treated via a transsphenoidal approach (47). Mullan treated carotid-cavernous fistulae by packing through the anterior-inferior venous space after removing the thin triangular area of bone between the superior and inferior orbital fissures (53).

The inferomedial transnasal approach may be used to expose the medial venous space, the anterior and medial surfaces of the anterior bend, and the medial surface of the horizontal segment. Via this exposure, it is possible to achieve access to the contralateral cavernous sinus through the sphenoid sinus or around the pituitary gland. Currently, 
endoscopic endonasal cavernous sinus surgery is another approach for the inferomedial region (3).

A middle cranial fossa meningioma invading the inferior portion of the cavernous sinus can be resected through the anterolateral triangle and the lateral triangle.

In cavernous sinus surgery, the operative field (triangle) is very important and can be enlarged by the mobilization of the cranial nerves after sufficient exposure of them. However, there is size and shape variation of the triangles. The anteromedial, superolateral (Parkinson's), and posteromedial (Kawase's) triangles have relatively consistent shapes compared to the other triangles.

It is clear that a single approach is not capable of providing exposure of all the parts of the sinus; however, a combination of the superior and lateral approaches provides the best exposure of the cranial nerves, the intracavernous carotid, and the venous space above, below, and lateral to the carotid artery (33). A precise understanding of the bony relationships and neurovascular content of the cavernous sinus, together with the use of cranial base and microsurgical techniques has allowed neurosurgeons to approach the cavernous sinus with reduced morbidity and mortality (80).

Despite advances in neuroimaging, neuroanesthesia, and microsurgical techniques, complications associated with direct operative procedures in the cavernous sinus region still remain high. New forms of therapy, such as stereotactic radiosurgery, endovascular techniques, and medical therapy in certain tumors provide alternatives for the management of these lesions.

\section{REFERENCES}

1. Abad JM, Alvarez F, Blazquez MG: An unrecognized neurological syndrome: sixth-nerve palsy and Homer's syndrome due to traumatic intracavernous carotid aneurysm. Surg Neurol 16:140-144, 1981

2. Adams J: Aneurism of internal carotid in the cavernous sinus causing paralysis of the third, fourth, fifth and sixth nerves. Lancet 2:768, 1869

3. Alfieri A, Jho HD: Endoscopic endonasal cavernous sinus surgery: An anatomic study. Neurosurgery 48:827-837, 2001

4. Al-Mefty O. Operative Atlas of Meningeomas. Philadelphia: Lippincott-Raven, 1998

5. Al-Mefty O: Surgery of the Cranial Base. Boston: Kluwer Academia Publishers, 1989

6. Bartholow R: Aneurisms of the arteries at the base of the brain, their symptomatology, diagnosis, and treatment. Am J Med Sci 64:373-386, 1872
7. Bedford MA: The "cavernous sinus." Br J Ophthalmol 50:4146, 1966

8. Borba LAB, AI-Mefty O: Normal anatomy of the cavernous sinus. In: Eisenberg ME, AI-Mefty 0, eds. The Cavernous Sinus: A Comprehensive Text. Philadelphia: Lippincott Williams \& Wilkins, 2000: 21-34

9. Cahill M, Bannigan J, Eustace P: Anatomy of the extraneural blood supply to the intracranial oculomotor nerve. $\mathrm{Br} \mathrm{J}$ Ophthalmol 80:177-181, 1996

10. Capo H, Kupersmith MI, Berenstein A, Choi IS, Diamond GA: The clinical importance of the inferolateral trunk of the internal carotid artery. Neurosurgery 28:733-737; discussion 737-738, 1991

11. Day JD: Microsurgical Dissection of the Cranial Base. New York: Churchill Livingstone, 1996

12. De Jesus O: The clinoidal space: Anatomical review and surgical implications. Acta Neurochir 139:361-365, 1997

13. Destrieux C, Velut S, Kakou MK, Lefrancq T, Arbeille B, Santini J: A new concept in Dorello's canal microanatomy: The petroclival venous confluence. J Neurosurg 87:67-72, 1997

14. Diaz FG, Ohaegbulam S, Dujovny M, Ausman JI: Surgical alternatives in the treatment of cavernous sinus aneurysms. J Neurosurg 71: 846-853, 1989

15. Dolenc VV: A combined epi- and subdural direct approach to carotid-ophthalmic artery aneurysms. J Neurosurg 62: 667672,1985

16. Dolenc VV (ed): Anatomy and Surgery of the Cavernous Sinus. Wien: Springer-Verlag, 1989: 1-341

17. Dolenc VV: Direct microsurgical repair of intracavernous vascular lesions. J Neurosurg 58: 824-831, 1983

18. Dolenc VV: General approach to the cavernous sinus. In: Anatomy and Surgery of the Cavernous Sinus. Wein: Springer-Verlag 139-169, 1989

19. Dolenc VV. Microsurgical Anatomy and Surgery of the Central Skull Base. Wien: Springer-Verlag, 2003

20. Frazier $\mathrm{CH}$ : The surgical treatment of intracranial lesions causing disturbances of vision. In: Posey WP, Spiller WG, eds. The Eye and the Nervous System. Philadelphia: JB Lippincott; 867-873, 1906

21. Fujii K, Chambers SM, Rhoton AL Jr: Neurovascular relationships of the sphenoid sinus: A microsurgical study. J Neurosurg. 50:31-39, 1979

22. Fukushima T: Direct operative approach to the vascular lesions in the cavernous sinus: summary of 27 cases. Mt Fuji Workshop. Cerebrovasc Dis 6:169-189, 1988

23. Goel A: The extradural approach to lesions involving the cavernous sinus. Br J Neurosurg 11 : 134-138, 1997

24. Goel A, Muzumdar DP, Nitta J: Surgery on lesions involving cavernous sinus. Journal of Clinical Neuroscience 8 (supplement 1) : 71-77, 2001

25. Hakuba A: Surgical approaches to the cavernous sinus via the medial triangles: Report of an aneurysm at the C4-C5 junction of the internal carotid artery. Geka Shinryo 26: 1385-1390, 1985

26. Hakuba A, Matsuoka Y, Suzuki T. Komiyama M, JiD TB, Inoue $Y$ : Direct approaches to vascular lesions in the cavernous sinus via the medial triangle. in Dolenc VV (ed): The Cavernous Sinus. Wien: Springer-Verlag, 1987: 272-284

27. Hakuba A, Nishimura S, Jang BJ: A combined retroauricular and preauricular trans petrosaltranstentorial approach to dival meningiomas. Surg Neurol 30: 108-116, 1988 
28. Hakuba A, Nishimura S, Shirakata S, Tsukamoto M: Surgical approaches to the cavernous sinus: Report of 19 cases. Neurol Med Chir (Tokyo) 22: 295-308, 1982

29. Hakuba A, Ohata K, Soares SB Jr: Embryology of the cavernous sinus. In: Eisenberg MB, Al-Mefty 0, eds. The Cavernous Sinus: A Comprehensive Text. Philadelphia: Lippincott Williams \& Wilkins, 2000: 5-20

30. Hakuba A, Tanaka K, Suzuki T, Nishimura S: A combined orbitozygomatic infratemporal epidural and subdural approach for lesions involving the entire cavernous sinus. J Neurosurg 71: 699-704, 1989

31. Harris FS, Rhoton AL Jr : Anatomy of the cavernous sinus: A microsurgical study. J Neurosurg 45:169-180, 1976

32. Hashimoto N, Kikuchi H: TraDssphenoidal approach to infrasellar tumors involving the cavernous sinus. J Neurosurg 73: 513-517, 1990

33. Inoue $\mathrm{T}$, Rhoton $\mathrm{AL}$, Theele D, Barry ME: Surgical approaches to the cavernous sinus: A microsurgical study. Neurosurgery 26: 903-932, 1990

34. Isolan GR, De Oliveira E, Mattos JP: Microsurgical anatomy of the arterial compartment of the cavernous sinus. Arq Neuropsiquiatr 63(2-A): 259-264, 2005

35. Isolan GR, Krayenbühl N, De Oliveira E, Al-Mefty O: Microsurgical anatomy of the cavernous sinus: Measurements of the triangels in and around it. Skull Base 17 (6):357-367, 2007

36. Jimenez-Castellanos J, Carmona A, Catalina-Herrera CJ: Anatomical study of the branches emerging along the intracavernous course of the internal carotid artery in humans. ActaAnat 148:57-61, 1993

37. Johnston I: Direct surgical treatment of bilateral intracavernous internal carotid artery aneurysms: Case report. J Neurosurg 51:98-102, 1979

38. Kawase T, van Loveren H, Keller JT, Tew JM: Meningeal architecture of the cavernous sinus: Clinical and surgical implications. Neurosurgery 39:527-534, discussion 534-536, 1996

39. Kehrli P, Ali MM, Maillot C, Fortman J, Misra M, Dujovny M: Comparative microanatomy of the lateral wall of the "cavernous sinus" in humans and the olive baboon. Neurol Res 19:571-576, 1997

40. Kehrli P, Ali M, Reis M Jr, Maillot C, Dietemann JL, Dujovny $\mathrm{M}$, Ausman JI :Anatomy and embryology of the lateral sellar compartment (cavernous sinus) medial wall. Neurol Res 20:585-592, 1998

41. Kehrli P, Maillot C, Wolff MJ : The venous system of the lateral sellar compartment (cavernous sinus): an histological and embryological study. Neurol Res 18:387-393, 1996

42. Keyes JEL: Observations on four thousand optic foramina human skulls of known origin. Arch Ophthalmol 13:538-568, 1935

43. Kim JM, Romano A, Sanan A, van Loveren HR, Keller JT : Microsurgical anatomic features and nomenclature of the paraclinoid region. Neurosurgery 46:670-680, discussion 680682,2000

44. Krisht A, Barnett DW, Barrow DL, Bonner G: The blood supply of the intracavernous cranial nerves: An anatomic study. Neurosurgery 34:275-279, 1994

45. Langworthy HG: Ocular relations of the cavernous sinus. In: Wood CA, ed. The American Encyclopedia of Ophthalmology. Vol III. Chicago: Cleveland Press 1914: 17941809
46. Lasjaunias P, Moret J, Mink J: The anatomy of the inferolateral trunk (IL T) of the internal carotid artery. NeuroradioJogy 13: 215-220, 1977

47. Laws ER Jr, Onofrio BM, Pearson BW, McDonald TJ, Dirrenberger RA: Successful management of bilateral carotidcavernous fistulae with a trans-sphenoidal approach. Neurosurgery 4:162-167, 1979

48. Mariniello G: Microsurgical anatomy of sympathetic fibres running inside the cavernous sinus. J Neurosurg Sci 38:1-10, 1994

49. Mariniello G, Annecchiarico H, Sardo L, Buonamassa S, de Divitiis E : Connections of sympathetic fibres inside the cavernous sinus: A microanatomical study. Clin Neurol Neurosurg 102:1-5, 2000

50. Matsuoka Y, Hakuba A, Kishi H, Nishimura S: Direct surgical treatment of intracavernous internal carotid artery aneurysms: Report of four cases. Surg Neurol 26: 360-364, 1986

51. McGratt P: The cavernous sinus: An anatomical survey. Aust NZ J Surg 47:601-613, 1977

52. Miyazaki Y, Yamamoto I, Shinozuka S, Sato O: Microsurgical Anatomy of the Cavernous Sinus. Neurol Med Chir (Tokyo) 34:150-163, 1994

53. Mullan S: Treatment of carotid-caveronus fistulas by cavernous sinus occlusion. J Neurosurg 50:131-144, 1979

54. Newman S: A prospective study of cavernous sinus surgery for meningiomas and resultant common ophthalmic complications (An american ophthalmogical society thesis). Trans Am Ophthalmol Soc 105: 392-447, 2007

55. Pait TO, Zeal A, Harris FS, Paullus WS, Rhoton AL: Microsurgical anatomy and dissection of the temporal bone. Surg Neurol 8: 363-391, 1977

56. Pamir N, Kilic T, Özek MM, Özduman K, Türe U: Nonmeningeal tumours of the cavernous sinus: A surgical analysis. Journal of Clinical Neuroscience 13:626-635, 2006

57. Parkinson D: A surgical approach to the cavernous portion of the carotid artery: Anatomical studies and case report. J Neurosurg 23:474-483, 1965

58. Parkinson D: Collateral circulation of cavernous carotid artery. Can J Surg 7 :251-268, 1964

59. Parkinson D: Bernard, Mitchell, Homer syndrome and others? Surg Neurol 11 :221-223, 1979

60. Parkinson D, Johnston J, Chaudhuri A: Sympathetic connections to the fifth and sixth cranial nerves. Anat Rec 191:221-226, 1978

61. Paullus WS, Pait G, Rhoton AL: Microsurgical exposure of the petrous ponion of the carotid anery. J Neurosurg 47: 713-726, 1977

62. Reisch R, Vutskits L, Patonay L, Fries G : The meningohypophyseal trunk and its blood supply to different intracranial structures. An anatomical study. Minim Invasive Neurosurg 39:78-81, 1996

63. Rhoton AL Jr: The supratentorial cranial space: Microsurgical anatomy and surgical approaches. Neurosurgery 21(suppll):375-410, 2002

64. Rhoton AL Jr, Hardy DG, Chambers SM: Microsurgical anatomy and dissection of the sphenoid bone, cavernous sinus, and sellar region. Surg Neurol 12:63-104, 1979

65. Rhoton AL Jr, Inoue T: Microsurgical approaches to the cavernous sinus. Clin Neurosurg 37:391-439, 1991 
66. Sekhar LN, Burgess J, Akin 0: Anatomical study of the cavernous sinus emphasizing operative approaches and related vascular and neural reconstruction. Neurosurgery 21: 806-816, 1987

67. Seoane E, Rhoton AL Jr, de Oliveira E: Microsurgical anatomy of the dural collar (carotid collar) and rings around the clinoid segment of the internal carotid artery. Neurosurgery 42:869884; discussion 884-886, 1998

68. Smith JL. Editorial note to: Post MID, Glaser JS, Trobe JD: Elusive lesions of the cavernous sinus. In: Smith JL, ed. Neuro ophthalmology Focus 1980. New York: Masson, 1979: 260

69. Taptas JN: The so-called cavernous sinus: A review of the contraversy and its implications for neurosurgery. Neurosurgery 11:712-717, 1982

70. Trobe JD, Glaser JS, Post JD: Meningiomas and aneurysms of the cavernous sinus. Neuro-ophthalmologic features. Arch Ophthalmol 96:457-467, 1978

71. Umansky F, Nathan H: The cavernous sinus. An anatomical study of its lateral wall. In: Dolenc VV, ed. The Cavernous Sinus. A Multidisciplinary Approach to Vascular and Tumorous Lesions. Wien: Springer-Verlag 1987: 56-66

72. Umansky F, Nathan H: The lateral wall of the cavernous sinus. With special reference to the nerves related to it. J Neurosurg 56:228-234, 1982

73. Umansky F, Valarezo A, Elidan J: The superior wall of the cavernous sinus: A microanatomical study. J Neurosurg 81:914-290, 1994
74. van Loveren HR, Keller JT, EI-Kalliny M, Scodary DJ, Tew JM Jr: The Dolenc technique for cavernous sinus exploration (cadaveric prosection). Technical note. J Neurosurg 74: 837844, 1991

75. van Overbeeke JJ, Dujovny M, Troost D: Anatomy of the sympathetic pathways in the cavernous sinus. Neurol Res 17:2-8, 1995

76. Wallace S, Goldberg HI, Leeds NE : The cavernous branches of the internal carotid artery. Am J Roentgenol Radillm Ther Nucl Med 101 :34-46, 1967

77. Watanabe A, Nagaseki Y, Ohkubo S, Ohhashi Y, Horikoshi T, Nishigaya K, Nukui H: Anatomical variations of the ten triangles around the cavernous sinus. Clin Anat 16:9-14, 2003

78. Weninger WJ, Muller GB: The parasellar region of human infants: Cavernous sinus topography and surgical approaches. J Neurosurg 90:484-490, 1999

79. Weninger WJ, Streicher J, Muller GB: Anatomical compartments of the parasellar region: Adipose tissue bodies represent intracranial continuations of extracranial spaces. J Anat $191: 269-275,1997$

80. Yasuda A, Campero A, Martins C, Rhoton AL, de Oliveira E, Ribas GC: Microsurgical anatomy and approaches to the cavernous sinus. Neurosurgery 56:4-27, 2005

81. Ziyal IM, Salas E, Wright DC, Sekhar LN :The petrolingual ligament: the anatomy and surgical exposure of the posterolateral landmark of the cavernous sinus. Acta Neurochir 140:201-204; discussion 204-205, 1998 